\title{
NIGHT DELIVERIES AND CARRIER-LED CONSOLIDATION STRATEGIES TO IMPROVE URBAN GOODS DISTRIBUTION
}

\author{
Miquel ESTRADA*, José-Magín CAMPOS-CACHEDA, Francesc ROBUSTÉ \\ Dept of Civil and Environmental Engineering, Polytechnic University of Catalonia, Barcelona, Catalonia, Spain
}

Received 27 July 2017; revised 30 August 2017; accepted 3 October 2017

\begin{abstract}
Night distribution and consolidation strategies have been proposed in many cities to increase the efficiency of the urban goods distribution system and to reduce the external effects that it causes in terms of emissions. However, the deployment of these initiatives presents a new reallocation of costs and incomes among collaborative stakeholders that take part in. In this paper, an analytical model to estimate the new economic effects caused by these strategies on the involved agents is presented, based on continuous approximations. This model allows decision makers to estimate the transportation cost and emissions savings that will be obtained by each strategy as well as the range of retailer demand in which these strategies are not economically feasible. The results show that night distribution generally outperforms the carrier cost reduction and emissions savings, especially when large vehicles are used in night periods.
\end{abstract}

Keywords: urban goods distribution, stakeholder collaboration, consolidation, night deliveries, air quality.

\section{Introduction}

The distribution of products in metropolitan areas is expected to increase in the next years in absolute values [tones], frequencies and quality requirements, according to the concentration of population in these areas (Barone, Roach 2016; Van Audenhove et al. 2015). The e-commerce growth and the new characteristics of supply chains (justin-time, stock 0 , distribution in narrow time windows) will also put more pressure on the physical distribution of goods in urban crowded areas (Allen et al. 2018).

Following system engineering principles, the goods distribution in a city should use a set of resources (vehicles, energy, personnel, urban space) to provide an adequate service according to the expected demand of products (Foltyński 2016; Kawamura 2014). Since the goods distribution is the physical reflection of economic relationships among stakeholders, any inefficient or insufficient provision of freight services may result in a reduction of the economic activity in the city (Taniguchi 2014). However, urban goods distribution generates multiple negative effects, worsening the environment and liveability of agglomerations in terms of congestion, air quality, noise nuisance and pavement deterioration (Schoemaker et al. 2006; NCFRP 2012). In this context, transport policies should promote the maximization of the product economy profit as well as the minimization of negative externalities that would affect the social welfare (HolguínVeras, Sánchez-Díaz 2016).

In order to tackle the rising environmental and liveable conflicts of goods distribution in urban areas, there is a wide set of ecological innovation measures promoted by local agencies with the support of national and supranational funds. Several European projects have analysed the results of new logistic measures implemented in cities (Allen et al. 2007; STRAIGHTSOL 2014; CITYLOG 2013; SMARTFREIGHT 2016). In Holguín-Veras et al. (2015), 54 different good distribution strategies are identified. For each of them, an analysis of the major potentialities and weaknesses is provided. Due to the presence of multiple stakeholders with opposite objectives, and the lack of exante assessment methodologies to estimate the potential impacts of initiatives on each agent, the results achieved vary significantly and depend on the site's physical characteristics and the organizational framework.

From a global perspective, the costs and emissions incurred by a carrier distributing parcels to a set of customers, is usually considered a function of the total number of kilometres run and the time spent by the fleet, multiplied by the corresponding unit factor parameters (unit cost or

*Corresponding author. E-mails: miquel.estrada@upc.edu, miquel.estrada@gmail.com 
emission factors) (EMEP/EEA 2013). Cost and emission savings can be achieved through initiatives that propose the usage of an eco-friendly and efficient fleet (lower unit factors), with some temporal and spatial restrictions. However, these are just a partial solution for a more complex problem: the aforementioned new characteristics of supply chains have increased the commercial vehicle mileage. Therefore, a new radical change in the effects of goods distribution can only be achieved by promoting strategies that address the reduction of the total distance overcome by commercial vehicles. Nevertheless, these strategies usually involve a highly demanding scheme of collaboration among stakeholders or a new market situation, since any reduction of current vehicle routes need the voluntary or mandatory acceptance of carriers, retailers and suppliers (Holguín-Veras et al. 2015).

Two of the most controversial collaboration measures in urban distribution are night distribution and carrierled consolidation strategies. In SUGAR and STRAIGHTSOL projects, both solutions were widely analysed, tested and evaluated in several demonstrations (SUGAR 2011; STRAIGHTSOL 2014; Johansen et al. 2014). According to Holguín-Veras, Sánchez-Díaz (2016), the former solution is aimed at changing the timing of deliveries out of peak traffic hours while the latter tries to change the destination of supplies at a common facility, where products are consolidated. These solutions are currently incorporated into Urban Mobility Plans (UMPs) to tackle air quality problems in urban areas, based on the proved results obtained in different worldwide pilot tests. Unfortunately, the target emission and cost savings presented in these UMPs have not been properly estimated considering the particularities of each city. In fact, city councils often consider both measures valid solutions to reduce the externalities of urban goods distribution, not taking into account the urban logistics sector and the new required collaboration schemes among stakeholders in depth. Hence, economic tools to set target reductions are strongly needed by city councils as well as to identify which measure fits better to the situation of urban logistics in each city. In this context, the main motivation of this work is to help public authorities make a decision on new collaborative solutions for their city, as long as goods distribution policies are concerned. This assistance is made by identifying the most efficient collaborative strategy that responds to transport policy objectives, enabling to make an ex-ante assessment and comparison of the solutions by means of economic and environmental metrics for an urban good distribution strategy.

Therefore, this paper is aimed at providing robust estimations of emissions and operating cost savings caused by night distribution and consolidation strategies. An assessment model based on continuous approximations is developed for both strategies providing compact formulas dependent to a set of input parameters that define the kinematic and economic characteristics of goods distribution in each case site. It also captures the cash flows among stakeholders and their profitability due to the new collaborative scheme in urban goods distribution system. The analytical model allows comparing the achievements caused by both measures and identifying which solution would provide the highest cost and emission savings. In Section 1, the background and contributions related to both strategies are commented. The analytical model for night distribution and consolidation strategies is developed in Section 2. The comparative analysis of the results obtained by each strategy is developed in Section 3. Finally, the key issues regarding the implementation and achievements of both strategies are presented in the last section.

\section{Background}

The efficiency of urban goods distribution can be improved by means of a different collaborative relationship among stakeholders in multiple elements of the supply chains. Collaborating agents may share administrative practices (transactional collaboration), exchange information (informational collaboration) and even coordinate the supply chain planning (decisional collaboration) in order to achieve a common objective (Gonzalez-Feliu, Salanova 2012). There are two levels of collaboration (Gonzalez-Feliu et al. 2013a): Vertical collaboration, in which multiple stakeholders responsible for different stages of the supply chain cooperate in order to provide a better performance to final customers; and, horizontal cooperation where private or public bodies that belong to the same agent typology (supplier, receiver, carrier) work together at the same level of supply chain.

Off-Hours and night Distribution (OHD) of goods is a traditional vertical collaborative measure aimed at switching the deliveries from commercial hours to offpeak periods (Holguín-Veras et al. 2015). This solution increases the efficiency of the urban goods distribution system and improves the livability of cities, as environmental benefits are achieved (Holguín-Veras et al. 2017a; Yannis et al. 2006). This strategy is focused on carriers but need the involvement of retailers. In spite of the easiness of implementation, both, carriers and receivers, should be benefitted from this solution. According to HolguínVeras et al. (2017b), carriers are usually in favour of this initiative since deliveries are made in a higher productive time period, resulting in a reduction of the number of vehicles needed to fulfil all retailers' orders. In addition to that, carriers can be benefited by a higher availability of load/unload parking spaces since several street lanes in the peak hour can be used in night period for urban distribution (Holguín-Veras, Sánchez-Díaz 2016). For the city council, this measure is quite attractive since it alleviates congestion and emission episodes at the expenses of increasing the noise nuisance in the night period.

The main issue for the deployment of this initiative is the receivers' acceptance. Receivers may be benefitted by OHD in terms of reliability since they would have products delivered early in the morning (Holguín-Veras, 
Sánchez-Díaz 2016). In fact, any disturbance or failure in the supply of products can be fixed early in the morning, before the opening of the establishment. However, OHD usually implies additional personnel cost (present staff for receiving deliveries) and security cost (cameras and other devices) for receivers and increases the risk of property damage or theft at the shop where supplies are delivered (Holguín-Veras et al. 2017b). All these problems are more relevant for small retailers and local shops. On the contrary, big department stores may have personnel responsible for store replenishment that would receive the shipments out of the commercial hours. This statement is based on the current supply practice of supermarkets, clothes departments that everyone can notice at night in several European cities.

In order to compensate receivers for these effects, the deployment of this initiative should need the provision of monetary incentives in order to persuade retailers to take part in it. Several contributions have analysed the role of on-going monetary incentives to afford the new personnel cost when staff is receiving supplies at night, the new scheme of freight fares and the necessary conditions to promote night distribution (Holguín-Veras et al. 2007; Holguín-Veras, Aros-Vera 2015; Holguín-Veras et al. 2011; Brom et al. 2011). Alternatively, unattended deliveries can be performed by carriers at night period when retailers have a trust vendor. In these situations, receiver monetary incentives are only necessary one time (tax rebate or cash payment) in order to deploy the required security devices to receive products at night without the presence of staff. Monetary incentives can also be found as carrier fare discounts, since this agent may transfer a fraction of the operating cost savings to receivers.

Several contributions have been focused on the response of receivers and even carriers to night distribution based on discrete choice models (Holguín-Veras et al. 2008b), behaviour microsimulation (Silas, Holguín-Veras 2009) and upper bound estimations. A complete analysis of the acceptance of this solution by retailers is presented in Holguín-Veras et al. (2017a). From a survey conducted in New York (Holguín-Veras et al. 2013), the receiver's willingness to participate in unattended OHD would be $38 \%$ when a one- time incentive of $\$ 9000$ would be provided to each receiver. The receivers, which have a trusted vendor present a willingness 1.4 times higher to move to OHD. Therefore, the availability of a trusted vendor is an important fact to promote OHD. In a recent voluntary OHD program conducted in Manhattan in 2010, it has been demonstrated that those establishments that had staff present in the OHD, changed to regular-hour deliveries at the end of the pilot due to the personnel cost (once incentives were not available). On the contrast, retailers that had opted for unattended deliveries continued in the program once incentives were removed (Holguín-Veras et al. 2013).

From the carrier perspective, one of the main factors that determine the attractiveness of this solution is the spatial distribution of receivers within the area of service (Holguín-Veras 2011). If a specific region of the city has receivers to be served at regular and OHD periods, the distributing routes will overlap and carrier will incur in additional costs. Therefore, geographic-oriented incentives are needed to foster the participation of all receivers in a given region into the night distribution program.

The cost reduction of carriers, shippers and receivers caused by off-peak distribution initiative was estimated to be $\$ 100 \ldots 200$ million per year from the results of the pilot test in New York (Holguín-Veras et al. 2011). In other implementations in Sao Pablo and Bogotá, the cost savings experienced by carriers were around $30 \%$ and the local pollutants were reduced by $55 . . .65 \%$ - Holguín-Veras et al. (2016) from the results reported in CISLOG (2015) and Universidad Nacional de Colombia (2015). As a result of the promising achievements, other cities like Chicago, Boston, Atlanta, London, and Toronto are also analyzing the implementation of OHD while Copenhagen and Brussels have carried out pilot tests whose achievements are quite similar with the New York program (Holguín-Veras et al. 2017a).

The second urban distribution measure considered in this paper is the carrier-led consolidation strategy. Freight consolidation aims at reducing the number of commercial vehicles by grouping their loads into routes with higher load factor (Holguín-Veras, Sánchez-Díaz 2016). Receiverled consolidation combine shipments of different suppliers in order to reduce the number of incoming vehicles at a specific demand attraction pole, building or facility. This measure needs the leadership of receivers in order to change the purchasing policy to a given set of suppliers or consolidate their shipments before being distributed to the receiver locations. A successful implementation of this concept is identified in The Netherlands under the name Binnenstadservice case (Van Rooijen, Quak 2010). This solution can be considered an example of horizontal collaboration, since all receivers are coordinated to perform a common contracting and ordering policy to carriers.

Alternatively, the consolidation policy that has received more attention in the literature is the carrier-led consolidation strategy. It is based on pre-locations or facilities visited by multiple carriers where cargo is consolidated and loaded into vehicles that would perform the lastmile distribution to receivers scattered in an urban area (Holguín-Veras, Sánchez-Díaz 2016). This measure often implies the deployment of Consolidation Facilities (CFs) such as Urban Consolidation Centres (UCC) or Urban stage Areas (UsA) - Holguín-Veras et al. (2008a). In these urban facilities, goods are sorted and loaded into a new fleet managed by the CF operator. Then, this fleet, which usually consists of environmentally friendly vehicles, will deliver goods to the final retailers. This kind of consolidation strategy implies a strong horizontal collaboration among carriers visiting the CF. However, the reluctance of some shippers to take part in this new distribution system and the entrance of new agents to operate the CF (public 
authority, companies specialized in eco-friendly vehicles different from traditional carriers) imply a new vertical stakeholder collaboration in the supply chain.

In Browne et al. (2005), an extensive analysis of the potential effects of UCC on different stakeholders was conducted. They also justify, as a huge number of contributions do Allen et al. (2014) and Estrada, Roca-Riu (2017), that this strategy may reduce the local distance covered by regular carriers, can improve the efficiency and reduce the externalities caused by freight vehicles in urban areas. Consequently, the mileage and the emissions produced by urban distribution vehicles are also diminished in an urban area. One of the strengths of this strategy is that it is addressed to the agent that moves cargo and will experience the operating cost savings, i.e. carriers. A reduced number of carriers may be responsible for a large amount of shipments to be consolidated in the facility (Estrada, Roca-Riu 2017). In fact, carriers would pass the operating cost of distributing cargo from CF to receiver's location to a new stakeholder: the CF operator. Therefore, in the consolidation program, the CF operator will incur the costs associated to the last mile distribution as well as the fixed cost associated to run the CF. Economic compensations are needed under the form of carrier fares, receiver fees or subsidies in favour of CF operator. On the other hand, receivers are supposed to behave neutral against this policy since they do not receive any economic sign of the collaborative scheme. However, they can also be benefitted by the carrier-consolidation program since their business activity would not be as much interrupted as in regular distribution when this retailer receives a significant number of deliveries per day (Holguín-Veras, Sánchez-Díaz 2016). Nevertheless, the agent that would be negatively affected by the deployment of UCC or UsA is the shipper. The cargo transhipments at UCC make that shippers lose the product tracking and control in the last steps of the supply chain as well as the contact to the final customers. Therefore, shippers are reluctant to participate in consolidation programs that imply giving other companies a chance to contact their current customers (Navarro et al. 2016).

Regarding the distribution network planning based on a CF, the proper location of this centre is analysed in Gonzalez-Feliu et al. (2014). The estimation of the logistic cost and emission savings caused by consolidation programs by means of continuous approximations are presented in Roca-Riu, Estrada (2012), Roca-Riu et al. (2016), Estrada, Roca-Riu (2017) and Saberi, Verbas (2012). Janjevic, Ndiaye (2017) estimate the different cost components of those collaborating carriers when using a UCC.

In spite of the promising theoretical results, a high number of UCC pilot tests has not succeeded. From more than 75 UCC European initiatives analysed, only 25 were currently in service in 2011 (Gonzalez-Feliu et al. 2013b). Similar values can be identified in a worldwide UCC analysis (Allen et al. 2012). According to Holguín-Veras, Sánchez-Díaz (2016), this is due to the expensive space that UCC needs in the surroundings of the commercial area where retailers are located; and the additional logistic cost that the cargo transhipment implies. To overcome this problem, the deployment of a UCC needs the participation of multiple carriers, or alternatively the provision of public subsidies to receivers or CF operator. When these subsidies had been removed, the vast majority of UCC were no longer in service in a voluntary carrier consolidation program (Kin et al. 2016; Lebeau et al. 2017). In order to alleviate this problem, UsA, where a non-expensive structure is installed in an existing facility (parking, commercial mall) are becoming popular due to the lower investment needed (Holguín-Veras et al. 2008a; Navarro et al. 2016).

Other contributions proposed a mandatory consolidation measure in which regular carriers were forced to visit the UCC by regulation (Van Rooijen, Quak 2010; Quak, Tavasszy 2011). Therefore, a detailed study of the new cost and incomes allocation among collaborating stakeholders is needed to fulfil feasible UCC-UsA business models. This is partially addressed in several quantified assessments of the impacts of UCC in specific implementation cases in Europe, North American and Japan cities (Paddeu et al. 2014; Köhler 2001; Kawamura, Lu 2007; Chen et al. 2012; Gonzalez-Feliu, Morana 2011). However, the conclusions are somehow specific to each case study and it is difficult to extrapolate the achievements to other physical contexts.

\section{Profitability analysis of urban distribution measures}

The modelling approach to estimate the overall transportation cost and profitability for each stakeholder involved in the urban goods distribution system is developed in this section. Several models are proposed to that end, based on continuous approximations of the crucial system variables. The main general assumptions considered along the paper are commented below. We suppose that $M$ carriers provide freight transportation services in a compact region of a city of area $A$. The maximal allowable parcel volume to be served in regular distribution is $y_{\max }$. Each carrier $i(i=1, \ldots, M)$ is responsible of serving $N_{i}$ retailers that are uniformly distributed over the region of service. It is assumed that each receiver $k\left(k=1, \ldots, N_{i}\right)$ only orders one shipment per day, and the volume of this shipment $y_{k}$ is uniformly distributed in $y_{k} \in\left(0, y_{\max }\right)$. Therefore, the city presents a total demand of $N=\sum_{i=1}^{M} N_{i}$ that shipments will be served by different carriers. Hence, the total density of retailers to be served is equal to $\delta=\frac{N}{A}$. Let $F(y)$ be the cumulative distribution function of products whose volume is less or equal to $y_{\max }$ in the total area of service, satisfying $F(y=0)=0$ and $F\left(y=y_{\max }\right)=1$. The expectation of the volume of products demanded by one receiver in the region is estimated by $E(y)=\int_{0}^{y_{\max }} y \cdot f(y) d y$, where 
$f(y)$ is the corresponding probability density function of the parcel's volume. $F(y)$ and $f(y)$ are deterministic functions that can be defined taking into account the data of those parcels served by carriers.

In order to fulfil the distribution services required by all receivers $N$, we will consider three available distribution strategies:

- Strategy A. Regular Distribution. As in HolguínVeras (2008), this strategy represents the situation in which carriers visit the receiver's location along the commercial hours of shops, i.e. during the peak hour of traffic (generally from 8:00 AM to 6:00 PM). All stakeholders do business as usual, and there is no need of incentives or facilities deployment to promote a spatial or temporal shift of cargo deliveries. Therefore, Strategy A does not represent any kind of collaboration among stakeholders. Carrier's vehicles depart from a depot (distribution centre) located out of the city and visit the locations of receivers. When each vehicle has delivered all goods at the end of the tour, it returns to the distribution centre.

- Strategy B. Night Distribution. It consists of moving shipments of several carriers to the night or off-peak traffic period in order to take advantage of the faster cruising speeds and the greater availability of loading/ unloading parking slots. The spatial configuration of the distribution network is identical to Strategy A although the operation of this network at off-peak hours provides higher performance than Strategy A. As it is stated in Holguín-Veras, Aros-Vera (2015), some receivers are quite reluctant to take part in this initiative even if incentives will be provided. Hence, we consider that only a fraction $\mu(0 \leq \mu \leq 1)$ of the total number of receivers is distributed within the night period. The rest of receivers will be visited under regular conditions, in the same circumstances as in Strategy A.

- Strategy C. Distribution through a consolidation facility. It involves the aggrupation of several shipments belonging to different retailers and carriers into one commercial route that will visit final receivers. This strategy is aimed at incrementing the load factor of vehicles and reducing fleet size. Here, the spatial configuration of the distribution network is modified. We suppose that a new CF is deployed within the boundaries of the city of area A. This facility is operated by a new stakeholder: the CF operator. Considering Roca-Riu, Estrada (2012) and Browne et al. (2005), the entire number of deliveries is not suitable to be routed through the CF. The characteristics of freight (urgent, perishable, etc.) or receivers determine the viability of using the CF to fulfil the distribution service. Therefore, we consider that just a fraction of the total receivers will be served through the CF by the fleet managed by the CF operator. The rest of receivers will be visited by the carrier fleet in a similar way as in Strategy A. All receivers (served via $\mathrm{CF}$ or in regular conditions) will be visited during the commercial hours. The CF operator is responsible for the reception of shipments from many carriers at this facility, classification of the products with regard to the destination, loading these products into the last mile vehicles managed by CF operator and performing the routes from the $\mathrm{CF}$ to the final retailers to be visited. Therefore, regular carriers are no longer incurring the transportation cost associated to the local distribution of those products routed through the $\mathrm{CF}$ to the final retailers. However, each carrier $i=1, \ldots, M$ is supposed to pay a constant fare $\theta_{C F}$ per parcel to the CF operator in order to compensate the handling costs at the CF and the costs of the local distribution to the retailer location. The justification of this assumption is further explained in Estrada and Roca-Riu (2017).

Strategy A is considered as the base situation that represents the regular distribution performed by non-collaborative carriers. Hence, the profitability of each stakeholder in night distribution or consolidation strategies will be accounted, comparing several metrics estimated in this collaborative Strategy (B or C) and the corresponding variables in Strategy A.

In Strategy A, we suppose that vehicles depart from a depot (distribution centre) located at distance $\rho$ from the centre of the service area. As a difference from Robusté et al. (1990), we assume that the depot is deployed outside the city boundaries $(\rho>\sqrt{A})$. The transportation costs of one carrier $i$ in the regular distribution of Strategy A (Figure 1a) are proportional to the access distance $D_{L H, i}^{A}$ from the distribution centre to the distributing area in the city, the local distance within area $A$ to visit retailers $D_{L, i}^{A}$ and the service time $T_{i}^{A}$ (travel time and visiting time) according to Equation (1). Parameters $c_{d}[€ / \mathrm{veh} \cdot \mathrm{km}]$ and $c_{t}[€ /$ veh.h] capture the unit distance and temporal costs respectively.

$$
Z_{C, i}^{A}=c_{d} \cdot\left(D_{L, i}^{A}+D_{L H, i}^{A}\right)+c_{t} \cdot T_{i}^{A} .
$$

By means of continuous approximation models defined in Estrada, Roca-Riu (2017) and Roca-Riu et al. (2016), the access distance, the local distance and the service time in all routes can be estimated by Equations (2a), (2b) and (2c) respectively. We use the $L 1$ metric to determine the distance evaluation in the service area for the simplicity. The variable $\psi$ determines the maximal number of retailers that one vehicle is able to serve in the same tour, obeying the maximal volumetric constraints. In regular conditions, carriers will use a homogeneous fleet of capacity $C$. The vehicle capacity $C$ is defined as the total volume of parcels that one vehicle can carry. Therefore, $\psi=\frac{C}{E(y)}$ is the expected maximal number of receivers that one carrier tour is able to visit. Although variable $\psi$ would be also affected by temporal routing constraints, we consider in this paper that volumetric constraints are more severe than temporal constraints.

The mathematical operator $[x]^{+}$calculates the upper integer value of variable $x$. The parameters $v_{L}, v_{L H}$ corre- 
spond, respectively, to the cruising speed within the urban area $A$ and the access phase from distribution centre (out of the city) to the city boundaries. Eventually, the parameter $\tau$ captures the required time to perform one stop for visiting a retailer along the route.

$$
\begin{aligned}
& D_{L H, i}^{A}=2 \cdot \rho \cdot\left[\frac{N_{i}}{\psi}\right]^{+} ; \\
& D_{L, i}^{A}=\frac{2}{\sqrt{3}} \cdot\left(A \cdot N_{i}\right)^{1 / 2} ; \\
& T_{i}^{A}=\left(\frac{D_{L, i}}{v_{L}}+\frac{D_{L H, i}}{v_{L H}}\right)+\tau \cdot N_{i} .
\end{aligned}
$$

\subsection{Night distribution analysis (Strategy $B$ )}

We consider that only a fraction $\mu(0 \leq \mu \leq 1)$ of the total receivers $N$ to be served in the urban area can be visited in the night period. In this model, the distribution shift of one retailer from day to night period is randomly generated with a probability $\mu$ independently from the volume demanded of each retailer and the retailer location. Therefore, any receiver has the same probability to be served at night period. The pending of parcels $(1-\mu) \cdot N$ will be delivered to the final customers with the regular fleet during commercial hours.

The model to assess the profitability of night distribution addressed here is similar to the provided in HolguínVeras (2008). In the aforementioned contribution, compact formulas in order to estimate the operating cost are presented, depending on the range of overlapping regions served within day and night periods and the toll to be paid in regular distribution. In this paper, we do not consider any toll to be paid by carriers in day periods and the location of those retailers to be served at night is randomly chosen.

In Strategy B, carrier will operate two different networks. On one hand, the fraction of parcels $(1-\mu)$ will be served during the day period. We consider that there will be several retailers that will not switch to receiving night deliveries due to the extra cost that they may generate. The regular fleet of the carrier will overcome an access distance $D_{L H, i}^{B}$ and a local distance $D_{L, i}^{B}$ within the urban area, spending a total routing time $T_{i}^{B}$ (Figure $1 \mathrm{~b}$ ). The estimation of these variables can be made through Equations (2a)-(2c), replacing the variable $N_{i}$ by $N_{i} \cdot(1-\mu)$. On the other hand, the pending fraction of parcels $N_{i} \cdot \mu$ will be served during the night turn, taking advantage of the more productive period. In this phase, the vehicles will incur an access and local distance given by $D_{L H, i}^{B}$ and $D_{L, i}^{B}$ respectively. To do so, we suppose that the fleet will need a total amount of time $T_{i}^{N}$ to perform the overall parcels. In the night distribution, new unit cost $c_{d}^{N}$ and $c_{t}^{N}$ are considered, since the fleet typology chosen in the night period may be different from the one that operates the regular distribution. The estimation of the previous distances can be made identically to the daily period, considering a total number of retailers given by $N_{i} \cdot \mu$. However, the estimation of the travel time in the night period is provided in Equation (3), where $v_{L}^{N}, v_{L H}^{N}$ and $\tau^{N}$ parameters correspond to the cruising speed in the urban area, cruising speed in the access phase and stopping time for each retailer in the night period, respectively. We assume that these speeds will be higher than the corresponding values in the regular distribution due to the congestion episodes. Moreover, the night stopping time of vehicles at retailer locations is supposed to be lower than the same parameter at day operations, since there is more availability of load/unload parking slots. For the sake of simplicity we suppose that the distribution during the day period in Strategies A and B is performed with the same vehicle technology of capacity $C$.

$$
T_{i}^{N}=\left(\frac{D_{L, i}^{N}}{v_{L}^{N}}+\frac{D_{L H, i}^{N}}{v_{L H}^{N}}\right)+\tau^{N} \cdot N_{i} \cdot \mu .
$$

Therefore, the necessary condition to be fulfilled in Strategy B in order to ensure a positive profitability for carriers is stated in Equation (4). The $\eta_{N}$ variable, the ratio between the carrier cost in Strategy B (day and night deliveries) and the corresponding cost to Strategy A, must be lower than 1 to provide cost savings. However, considering externalities, Equation (5) determines the necessary condition in order to reduce the monetary cost of the emissions produced in Strategy B with regard to Strategy A by means of the $\eta_{E}$ ratio. In Equation (5), $\varepsilon\left(v_{L}\right)$ and $\varepsilon\left(v_{L H}\right)$ variables represent respectively the emission monetization of pollutants $\mathrm{CO}_{2}, \mathrm{NO}_{\mathrm{x}}$ and $\mathrm{PM}_{2.5}$ of the vehicles in the local distribution within the city boundaries and in the access phase from distribution centres to the city centre. The former variables can be estimated by $\varepsilon(v)=\left(€_{\mathrm{CO}_{2}} \cdot f_{\mathrm{CO}_{2}}(v)+€_{\mathrm{NO}_{\mathrm{X}}} \cdot f_{\mathrm{NO}_{\mathrm{X}}}(v)+€_{P M} \cdot f_{P M}(v)\right) \cdot D$, where $€_{x}$ is the emission cost of one kilogram of pol- a)

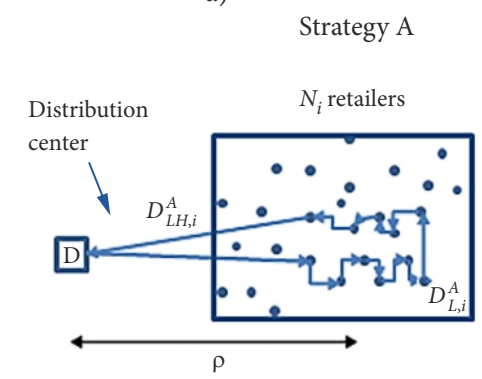

b)

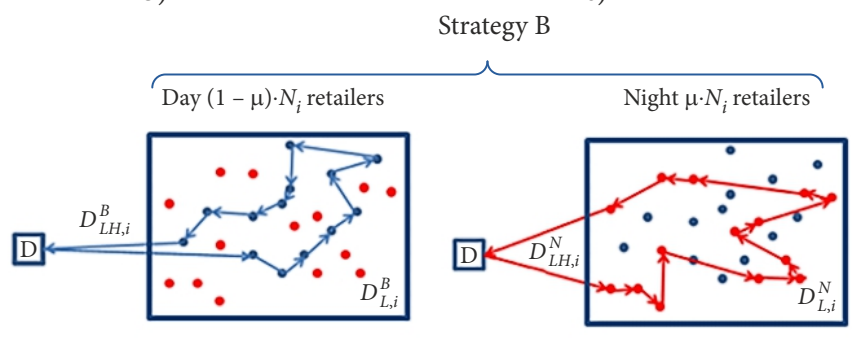

Figure 1. Comparison of distribution phases in Strategy A (a) and Strategy B (b and c) 
lutant $x(€ / \mathrm{kg} x), f_{x}(v)$ is the emission factor of pollutant $x$ associated to the vehicle fleet chosen $(\mathrm{kg} x / \mathrm{veh} \cdot \mathrm{km})$ and $D$ the distance overcome by the fleet under analysis (veh. km), estimated by Equations (2a) and (2b).

$\eta_{N}=\frac{c_{d}^{N} \cdot\left(D_{L}^{N}+D_{L H}^{N}\right)+c_{d} \cdot\left(D_{L H}^{B}+D_{L}^{B}\right)+c_{t}^{N} \cdot T^{N}+c_{t} \cdot T^{B}}{c_{d} \cdot\left(D_{L}^{A}+D_{L H}^{A}\right)+c_{t} \cdot\left(T^{A}\right)} \leq 1 ;$

$\eta_{E}=\frac{D_{L H}^{B} \cdot \varepsilon\left(v_{L H}\right)+D_{L H}^{N} \cdot \varepsilon\left(v_{L H}^{N}\right)+D_{L}^{B} \cdot \varepsilon\left(v_{L}\right)+D_{L}^{N} \cdot \varepsilon\left(v_{L}^{N}\right)}{D_{L}^{A} \cdot \varepsilon\left(v_{L}\right)+D_{L H}^{A} \cdot \varepsilon\left(v_{L H}\right)} \leq 1$.

The corresponding necessary conditions for retailers are not provided because they do not experience a cost variation. As it was commented from several pilot tests, several retailers experience higher reliability of supply chains when they receive products before starting the commercial shifts.

\subsection{Consolidation strategy analysis (Strategy C)}

The modelling approach of this collaborative urban distribution measure is identical to the methodology presented in Estrada and Roca-Riu (2017). However, in this paper we now complement the mathematical formulation to address the criteria by which the cost savings are divided into the different collaborative stakeholders (i.e. carriers and CF operator). We consider the same assumptions regarding demand distribution, number of carriers, characteristics of the carrier fleet and maximal product size delivered by carriers in Strategy A.

In this case, $\mathrm{CF}$ operator defines the maximal product volume $u_{\max }\left(u_{\max } \leq y_{\max }\right)$ that it is able to distribute with its own fleet to the final retailers. From the experience gathered in a pilot test conducted in Barcelona (Navarro et al. 2016), the size of the fleet typology chosen by CF operator is lower than the corresponding to carriers, since the former has to be adapted to the urban street layout. Therefore, given the maximal parcel volume admitted by CF operator, carriers usually route the smallest products through the $\mathrm{CF}$, while they operate with its own regular fleet the biggest products from distribution centres to the retailers' location. We suppose that all retailers ordering a parcel $y_{k} \leq u_{\max }$ will be routed through the CF and transhipped to the vehicles operated by CF operator.

Hence, $u_{\max }$ is considered a decision variable that strongly affects the CF operator profitability. Indeed, the fraction of deliveries routed through the CF from a single carrier $i(i=1, \ldots, M)$ is estimated by $F\left(y=u_{\max }\right)$, where $F(y)$ is the cumulative distribution function of the parcel volume. Therefore, the receiver suitability to be served through CF is based on the parcel volume demanded. This is a novel condition compared with Strategy B, where the fraction $\mu$ did not depend on the volumetric conditions of each receiver. On the contrary, each carrier will serve with the regular distribution network a total amount of $N_{i} \cdot\left(1-F\left(u_{\max }\right)\right)$ receivers whose parcel volume is $y_{k}>u_{\max }$.

The major economic changes on stakeholders caused by Strategy C are addressed by comparison to the regular distribution. Regular distribution is equivalent to the Strategy A, in which all shipments are distributed during commercial hours by regular carriers (Figure 2a). In Strategy $\mathrm{C}$, we suppose that all carriers may distribute the same fraction of products $F\left(u_{\max }\right),\left(0 \leq F\left(u_{\max }\right) \leq 1\right)$, through the CF. The pending products $N_{i} \cdot\left(1-F\left(u_{\max }\right)\right)$ of a carrier $i$ will be distributed using the regular carrier fleet (as in Strategy A). We suppose that each carrier pays a flat fare $\theta_{C}$ to CF operator for each parcel distributed through $\mathrm{CF}$. Therefore, in this Strategy C, the income experienced by the CF operator due to the unit fare per parcel will be $\theta_{C F} \cdot N \cdot F\left(u_{\max }\right)$. Considering the new operational scheme of Strategy C, we may identify three different route stages. The first one consists of the distribution of products from the distribution centres in the surroundings of the city to the CF (Figure $2 b$ ), where the fleet of each collaborating carrier $i(i=1, \ldots, \mathrm{M})$ will run over a distance $D_{L H, i}^{C}$ spending a total travel time $T_{i}^{C}$. The second stage (Figure $2 c$ ) is characterized by the regular distribution of those products that carrier $i(i=1, \ldots, \mathrm{M})$ cannot distribute through the CF. Carriers must use an additional fleet to deliver these fraction of products $N_{i} \cdot\left(1-F\left(u_{\max }\right)\right)$ to the final retailers, overcoming an access distance to the city $D_{L H, i}^{R}$, and a local distance within the city lim- a)

Strategy A b) c)

Strategy C d)

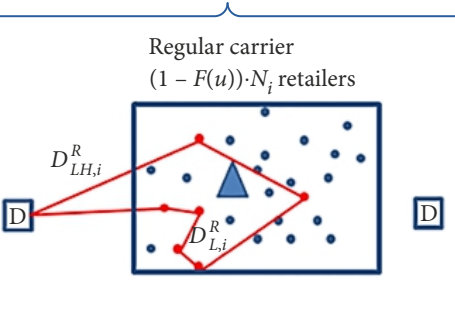

CF operator $F(u) \cdot N_{i}$ retailers

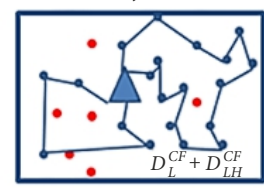

CF location

Figure 2. Comparison of distribution phases in Strategy A (a) and Strategy C (b - cooperative carrier, $c$ - regular carrier, $d$ - CF operator) 
its $D_{L, i}^{R}$. The total time spent in this stage is captured by $T_{i}^{R}=\frac{D_{L, i}^{R}}{v_{L}}+\frac{D_{L H, i}^{R}}{v_{L H}}+\tau \cdot N_{i} \cdot\left(1-F\left(u_{\max }\right)\right)$. Eventually, the third stage (Figure 2d) is the one operated by the CF operator. The urban fleet of the $\mathrm{CF}$ operator distributes all products consolidated at the CF belonging to all $M$ collaborating carriers $N \cdot F\left(u_{\max }\right)$ from the CF to the final retailers. In this stage, the total distance covered is $D_{L}^{C F}+D_{L H}^{C F}$ (local and access distance from CF location to each distribution zone) and the required distributing time is $T^{C F}$. In this case, we suppose a new unit distance and new temporal costs $c_{d}^{C F}, c_{t}^{C F}$ different from the regular carrier fleet. Moreover, the CF operator will incur a new daily cost $\Omega$ (€/day) associated to the facility investment and operating cost. The local and access distance as well as the routing time estimations can be made using Equations $(2 \mathrm{a}-\mathrm{c})$; replacing the number of retailers $N_{i}$, the maximal number of retailers that a vehicle can serve in one tour $\psi$ and the stopping time to serve each retailer $\tau$ by the corresponding parameter to each situation, stakeholder and fleet typology.

For a given city, the consolidation strategy (Strategy C) should guarantee a positive profitability to all stakeholders involved: collaborative carriers, CF operator and the city itself. Retailers are excluded from this analysis since they do not experience any transportation cost modification. The necessary condition to be fulfilled in order to ensure a positive profitability for carrier $i(i=1, \ldots, \mathrm{M})$ is that the quotient between the costs of Strategy $\mathrm{C}$ and the corresponding to Strategy A, denoted by $\eta_{C}$, should be lower than 1 (Equation 6). The necessary condition for a city is that the quotient $\eta_{E, C}$ between the monetary cost of the emissions in Strategy C and Strategy A must be lower than $1\left(\eta_{E, C} \leq 1\right.$ in Equation (7)). The variable $\varepsilon^{C F}\left(v_{L}\right)$ represents the emission monetary cost estimation of pollutants $\mathrm{CO}_{2}, \mathrm{NO}_{\mathrm{x}}$ and $\mathrm{PM}_{2.5}$ caused by the fleet managed by $\mathrm{CF}$ operator. Finally, the necessary condition to ensure that the incomes from carriers' fare are greater than the operating and investment cost incurred by $\mathrm{CF}$ operator is stated in Equation (8) $\left(\Delta_{C F}>0\right)$. The term $S_{C F}$ captures the potential subsidies or other incomes that $\mathrm{CF}$ operator can experience from other stakeholders (advertisements, etc.).

$$
\eta_{C, i}=\frac{a}{b} \leq 1, \forall i
$$

where:

$$
\begin{aligned}
& a=c_{d} \cdot\left(D_{L H, i}^{C}+D_{L H, i}^{R}+D_{L, i}^{R}\right)+ \\
& c_{t} \cdot\left(T_{i}^{C}+T_{i}^{R}\right)+\theta_{C F} \cdot N_{i} \cdot F\left(u_{\max }\right) ; \\
& b=c_{d} \cdot\left(D_{L, i}^{A}+D_{L H, i}^{A}\right)+c_{t} \cdot T_{i}^{A} ; \\
& \quad \eta_{E, C}=\frac{a}{b} \leq 1,
\end{aligned}
$$

where:

$$
\begin{aligned}
& a=\sum_{i=1}^{M}\left(\left(D_{L H, i}^{C}+D_{L H, i}^{R}\right) \cdot \varepsilon\left(v_{L H}\right)+\right. \\
& \left.\left(D_{L}^{C F}+D_{L H}^{C F}\right) \cdot \varepsilon^{C F}\left(v_{L}\right)+D_{L, i}^{R} \cdot \varepsilon\left(v_{L}\right)\right) ;
\end{aligned}
$$

$$
\begin{aligned}
b= & \sum_{i=1}^{M}\left(D_{L, i}^{A} \cdot \varepsilon\left(v_{L}\right)+D_{L H, i}^{A} \cdot \varepsilon\left(v_{L H}\right)\right) ; \\
& \Delta_{C F}=\left(\sum_{i=1}^{M} \theta_{C F} \cdot N_{i} \cdot F\left(u_{\max }\right)\right)+S_{C F}- \\
& c_{d}^{C F} \cdot\left(D_{L}^{C F}+D_{L H}^{C F}\right)-c_{t}^{C F} \cdot T^{C F}-\Omega \geq 0 .
\end{aligned}
$$

The necessary conditions defined through Equations (6)-(8) depend on two decision variables that define the collaboration between carriers and CF operator. The first one is the maximal parcel volume that is accepted at CF, that defines the fraction of parcels $F\left(u_{\max }\right)$ that will be routed through the CF. The second variable is the fare $\theta_{C F}$ that collaborating carriers are going to pay to $\mathrm{CF}$ operator for handling parcels and routing them to the final retailers. This fare $\theta_{C F}$ should satisfy two conditions: (1) it should be higher than the average transport cost per parcel that the CF operator incurs $z^{C F}$ and (2) it should be lower than the transportation cost saving per parcel that collaborating carrier will experience when it moves from Strategy A to Strategy $\mathrm{C}-\Delta z^{C A}$. Therefore, the actual fare should range in the domain $z^{C F} \leq \theta_{C F} \leq \Delta z^{C A}$. The determination of this fare within the previous domain constraints the allocation of the benefits among collaborating stakeholders. The higher boundary implies that all the benefits of Strategy $C$ are allocated to $C F$ operator through the fare $\theta_{C F}$, and collaborating carriers do not foresee any cost variation when passing from Strategy A to Strategy C. The lower boundary represents that the CF operator's incomes coming from the fare $\theta_{C F}$ are equal to the costs that this agent will incur. In this situation, the collaborating carriers will experience the highest profitability of their participation in this initiative.

In order to analyse different collaboration schemes between carriers and CF operator, we propose two criteria to determine the fare $\theta_{C F}$ in Strategy C:

- The first criterion, called MinFare, sets the fare equal to the average cost per parcel incurred by CF operator when operating the consolidation service, i.e. $\theta_{C F}=z^{C F}$. The carrier profitability is analysed for a wide domain of retailer density, although carrier cost savings are not achieved in multiple combinations of input parameters.

- The second criterion distributes the cost savings achieved by consolidation strategies to both carrier and CF operator. The analysis is only performed when the unit cost savings experienced by a collaborating carrier is higher than the unit cost incurred by CF operator, $\Delta z^{C A} \geq z^{C F}$. As carrier has become the agent that presents more inconveniences to accept the new distribution scheme of Strategy C, we define $\theta_{C F}=z^{C F}+0.3 \cdot\left(\Delta z^{C A}-z^{C F}\right)$. This criterion, referred to Fare30-70, proposes a good incentive for carriers to move from Strategy A to Strategy C. Only the $30 \%$ of the available cost savings per parcel resulting from this new scheme will be actually allocated to CF operator by means of the fare $\theta_{C F}$. 


\section{Discussion}

A sensitivity analysis of the profitability of the main stakeholders is presented with regard to the number of retailers that are going to be served with the collaborating Strategy $B$ and $C$. This number of retailers will be a function of the density of retailers to be visited in one day and the fraction of them that are going to be served by Strategy B (night distribution) or Strategy C (through a CF).

For all strategies A, B and C, we consider that retailers are scattered in a rectangle-shaped city of area A $=3 \times 2 \mathrm{~km}^{2}$. A set of $M=10$ carriers with the same market share is considered to distribute parcels to retailers in the same city of area $A=3 \times 2 \mathrm{~km}^{2}$. The total density of retailers served by all carriers ranges $\delta \in[1,1000]$ receiv$\mathrm{ers} / \mathrm{km}^{2}$; then, the corresponding density served by one carrier is $\delta_{i}=\frac{\delta}{10} \in[0.1,100]$ receivers $/ \mathrm{km}^{2}$. Therefore, the range of customer's density is identical for all Strategies $\mathrm{A}, \mathrm{B}$ and $\mathrm{C}$. The distribution centres of all carriers are supposed to be located at $20 \mathrm{~km}$ away with regard to the centre of the rectangular area. In regular conditions, the cruising speed in the access and local network during commercial hours is respectively $v_{L H}=60 \mathrm{~km} / \mathrm{h}$ and $v_{L}=20 \mathrm{~km} / \mathrm{h}$. The corresponding stopping time to visit one retailer in the regular distribution is $\tau=0.05 \mathrm{~h}$. The parameters are proposed to represent the regular kinematic characteristics of urban distribution, according to a pilot test conducted in Barcelona in 2014 (Navarro et al. 2016). We suppose that the shipment size demanded by each receiver $y_{k}$ is a random variable that is distributed uniformly in the domain $(0 ; 0.3] \mathrm{m}^{3}$. The maximal threshold is defined according to the actual maximal package size handled by a well-known logistics service provider in normal conditions (DHL 2013).

In Strategy B, we analyse the profitability of a single collaborative carrier $i(i=1, \ldots, 10)$ as a function of the spatial density of retailers and the fraction of receivers that moved to night distribution strategy $\mu \in[0,1]$. In the analysis of night distribution, two scenarios are considered. On one hand, Scenario 1.1 determines that the carrier will use a common fleet technology in the day and night distribution period of capacity $C=9 \mathrm{~m}^{3}$ (light truck) and unit cost parameters $c_{d}=0.28 € / \mathrm{veh} \cdot \mathrm{km}$ and $c_{t}=23.49 € / \mathrm{veh} \cdot \mathrm{h}$. Therefore, it needs the same typology of fleet as in Strategy A. These factors have been defined considering the results of a regional freight transport observatory conducted in Catalonia (Spain), (Generalitat de Catalunya 2015). On the other hand, in Scenario 1.2, we consider that the collaborative carrier will operate the night distribution with commercial vehicles of higher capacity, $C^{N}=25 \mathrm{~m}^{3}$, that corresponds to a medium truck. The agreement between metrics of Scenarios 1.1 and 1.2 will measure the effect of enlarging the fleet size in the night distribution on carrier's cost. It is supposed that carriers will need less vehicles to operate the service, resulting in lower mileage and emissions. However, the effect on transportation cost is not clear in advance, since different unit cost parameters for these vehicles have to be considered in the night distribution period $\left(c_{d}^{N}=0.36 € /\right.$ veh $\times \mathrm{km}$ and $c_{t}^{N}=27.89 € / \mathrm{veh} \times \mathrm{h}$ ) according to Generalitat de Catalunya (2015). The crucial issues in the analysis of Scenario 1.1 and 1.2 are the determination of cruising speeds at night period, which are higher than the corresponding values in the daily distribution and lower stopping times: $v_{L}^{N}=30 \mathrm{~km} / \mathrm{h}, v_{L H}^{N}=80 \mathrm{~km} / \mathrm{h}$ and $\tau^{N}=0.5 \cdot \tau$.

In the consolidation strategy (Strategy $\mathrm{C}$ ), the deployment of an UsA in the city has a corresponding facility cost of $\Omega=46 € / \mathrm{h}$ (Navarro et al. 2016). This value takes into account the operating and depreciation cost of the equipment needed. We suppose that regular carriers operate the distribution network under Strategy A with the same fleet of capacity $C=9 \mathrm{~m}^{3}$. Three different scenarios are proposed regarding the $\mathrm{CF}$ operator fleet technology, defined by its capacity, cost parameters and energy used. In Scenario 2.1, we consider that the fleet used by the CF operator to distribute products from $\mathrm{CF}$ to the final retailers is maintained as in Strategy A. This fleet consists of diesel-powered engine vehicles with a volumetric capacity $C_{C F}=9 \mathrm{~m}^{3}$. In Scenario 2.2, the CF operator fleet is replaced by fully electric vans of capacity $C_{C F}=2.16 \mathrm{~m}^{3}$, $c_{d}^{C F}=0.032 € / \mathrm{veh} \cdot \mathrm{km}$ and $c_{t}^{C F}=22.14 € / \mathrm{veh} \cdot \mathrm{h}$. This scenario represents that all CF fleet is electric and does not contribute to worsen the air quality of the urban area. Note that the vehicle capacity considered in Scenario 2.2 is less than the corresponding value in Scenario 2.1 because of the limited availability of fully-electric commercial vehicles. As far as the authors are concerned, there is not any fully electric truck of capacity $C_{C F}=9 \mathrm{~m}^{3}$ or higher in the market. Therefore, the agreement between Scenario 2.1 and 2.2 will capture the effect of replacing ICE vehicles by full electric vehicles on carriers cost and environment. The unit distance cost has been defined according to the average electric vehicle consumption per $\mathrm{km}$ and the average electricity fares $[€ / \mathrm{kW} \cdot \mathrm{h}]$ in Spain. Finally, Scenario 2.3 explores the usage of electric cargo bikes in the last mile distribution performed by the CF operator. As this fleet is allowed to run along the sidewalks and it can be parked in front of retailer's shops, we considered that the stop time per receiver $\tau^{C F}$ is one half of the corresponding parameter in Strategy A. Cruising speeds are conservatively considered to be the same as regular carrier fleet (Strategy A). This fleet will present the lowest vehicle capacity and unit cost parameters: $C_{C F}=1.2 \mathrm{~m}^{3}, c_{d}^{C F}=0.015 € / \mathrm{veh} \cdot \mathrm{km}$ and $c_{t}^{C F}=15.54 € / \mathrm{veh} \cdot \mathrm{h}$. The agreement of Scenarios 2.3 and 2.2 will explain the effect of reducing the unit cost parameters of the CF electric fleet on environment and carrier profitability. All input parameters are defined in Table 1.

\subsection{Night distribution measure. Strategy B}

The results of night distribution measure in Scenario 1.1 are plotted in Figure $3 \mathrm{a}\left(\eta_{N}\right.$ ratio $)$ and $3 \mathrm{~b}\left(\eta_{E}\right.$ ratio). These ratios determine the carrier cost and emission savings achieved by Strategy B with regard to Strategy A. The boundaries between different value ranges of both ratios depicted in Figures $3 \mathrm{a}, 3 \mathrm{~b}, 4 \mathrm{a}$ and $4 \mathrm{~b}$ present multiple discontinuities. 
Table 1. Summary of the input parameters considered in the analysis

\begin{tabular}{|c|c|c|}
\hline Notation & Concept & Numerical values \\
\hline \multicolumn{3}{|c|}{ City } \\
\hline$A$ & Area of the city $\left[\mathrm{km}^{2}\right]$ & 6 \\
\hline$y_{\max }$ & Maximal parcel volume to be distributed in the city by regular carriers in Strategy A $\left[\mathrm{m}^{3}\right]$ & 0.3 \\
\hline \multicolumn{3}{|c|}{ Carrier } \\
\hline$M$ & Number of collaborating carriers & 10 \\
\hline$\phi_{i}=\frac{N_{i}}{N}$ & Market share of each collaborating carrier $i(i=1, \ldots, M)$ & $\theta_{i}=0.1$ \\
\hline$\rho_{i}$ & $\begin{array}{l}\text { Distance between distribution centre and gravity centre of the distribution area within the } \\
\text { city }[\mathrm{km}]\end{array}$ & 20 \\
\hline$c_{t}$ & Unit temporal cost of regular carrier vehicles in the day distribution, Strategy A [€/veh $\cdot \mathrm{h}]^{\star 1}$ & 23.49 \\
\hline$c_{d}$ & Unit distance cost of regular carrier vehicles in the day distribution, Strategy A [€/veh·km] $]^{*}$ & 0.280 \\
\hline$c_{t}^{N}$ & Unit temporal cost of carrier vehicles used in night distribution, Strategy B [€/veh·h] ${ }^{* 1}$ & $\begin{array}{l}23.49 \text { (Scenario 1.1); } \\
27.89 \text { (Scenario 1.2) }\end{array}$ \\
\hline$c_{d}^{N}$ & Unit distance cost of carrier vehicles used in night distribution, Strategy B $[€ / \mathrm{veh} \cdot \mathrm{km}]^{*}$ & \begin{tabular}{|l|}
0.280 (Scenario 1.1); \\
0.36 (Scenario 1.2) \\
\end{tabular} \\
\hline$C$ & Capacity of the carrier vehicle used in the regular distribution, Strategy A $\left[\mathrm{m}^{3}\right]^{* 1}$ & 9 \\
\hline$C^{N}$ & Capacity of the carrier vehicle used in night distribution, Strategy $B\left[\mathrm{~m}^{3}\right]^{* 1}$ & $\begin{array}{l}9(\text { Scenario } 1.1) \\
25(\text { Scenario } 1.2)\end{array}$ \\
\hline$v_{L}, v_{L H}$ & $\begin{array}{l}\text { Cruising speed of the regular carrier vehicles in the local and access distribution phase, } \\
\text { day conditions, Strategy A }[\mathrm{km} / \mathrm{h}]\end{array}$ & 20,60 \\
\hline $\begin{array}{l}v_{L}^{N} \\
v_{L H}^{N}\end{array}$ & $\begin{array}{l}\text { Cruising speed of the carrier vehicles in the local and access distribution phase, night } \\
\text { conditions, Strategy B }[\mathrm{km} / \mathrm{h}]\end{array}$ & $30,80($ Scenario 1$)$ \\
\hline$\tau$ & Time needed by regular carrier vehicle to perform a retailer delivery [h] & 0.05 (all strategies) \\
\hline$\tau^{\prime}$ & Time needed by cooperative carrier vehicle to visit the CF, Strategy $\mathrm{C}[\mathrm{h}]$ & 0.25 (Scenario 2) \\
\hline$\tau^{N}$ & Time needed by carrier vehicle to perform a retailer delivery at night period, Strategy B [h] & 0.025 (Scenario 1$)$ \\
\hline $\begin{array}{r}e_{j}\left(v_{L}\right) \\
e_{j}\left(v_{L H}\right)\end{array}$ & $\begin{array}{l}\text { Emission factor of pollutant } j \text { corresponding to carrier vehicle cruising at speed } v_{L} \text { (local) } \\
\text { and } v_{L H} \text { (access) [g of pollutant } j / \mathrm{veh} \cdot \mathrm{km} \text { ] }\end{array}$ & \\
\hline- & $\mathrm{CO}_{2} / \mathrm{NO}_{\mathrm{x}} / \mathrm{PM}_{2.5}$ emission factor $[\mathrm{g} / \mathrm{veh} \cdot \mathrm{km}]^{\star 2}$ in local distribution & $293.32 / 0.724 / 0.00188$ \\
\hline- & $\mathrm{CO}_{2} / \mathrm{NO}_{\mathrm{x}} / \mathrm{PM}_{2.5}$ emission factor $[\mathrm{g} / \mathrm{veh} \cdot \mathrm{km}]^{\star 2}$ in access distribution & $193.026 / 0.626 / 0.00089$ \\
\hline \multicolumn{3}{|c|}{ CF operator, Strategy $C$} \\
\hline$c_{t}^{C F}$ & Unit temporal cost of CF operator vehicles $[€ / \mathrm{veh} \cdot \mathrm{h}]^{{ }^{*}}{ }^{1}$ & $\begin{array}{l}23.49 \text { (Scenario 2.1); } \\
22.14 \text { (Scenario 2.2); } \\
15.54 \text { (Scenario 2.3) }\end{array}$ \\
\hline$c_{d}^{C F}$ & Unit distance cost of CF operator vehicles $[€ / \mathrm{veh} \cdot \mathrm{km}]$ & $\begin{array}{l}0.280 \text { (Scenario 2.1); } \\
0.032 \text { (Scenario 2.2); } \\
0.015 \text { (Scenario 2.3) }\end{array}$ \\
\hline$C^{C F}$ & Capacity of the CF operator vehicle $\left[\mathrm{m}^{3}\right]$ & $\begin{array}{l}9 \text { (Scenario } 2.1) ; \\
2.16 \text { (Scenario } 2.2) ; \\
1.20 \text { (Scenario } 2.3)\end{array}$ \\
\hline$\Omega$ & Facility cost $[€ /$ day $]$ & 46.00 \\
\hline$\theta_{C F}$ & Fare per parcel to be paid by collaborating carrier [€/parcel] & variable \\
\hline$\tau^{C F}$ & Time needed by CF operator vehicle to perform a retailer delivery [h] & 0.025 \\
\hline$e_{j}^{C F}(v)$ & $\begin{array}{l}\text { Emission factor of pollutant } j \text { corresponding to CF operator vehicle cruising at speed } v_{L} \\
\text { (local) }[\mathrm{g} \text { of pollutant } j / \mathrm{veh} \times \mathrm{km} \text { ] }\end{array}$ & $\begin{array}{l}293.32 / 0.724 / 0.00188 \\
(\text { Scenario } 2.1) ; \\
0 \text { (Scenarios } 2.2 \text { and } 2.3) \\
\end{array}$ \\
\hline \multicolumn{3}{|c|}{ Externalities } \\
\hline \multirow{4}{*}{$\$_{j}$} & \multicolumn{2}{|l|}{ Monetary cost of pollutant $j:$} \\
\hline & monetary $\mathrm{CO}_{2}$ weighting factor $[€ / \mathrm{kg}]^{* 3}$ & 0.00768 \\
\hline & monetary $\mathrm{NO}_{\mathrm{x}}$ weighting factor $[€ / \mathrm{kg}]^{\star 4}$ & 6.3 \\
\hline & monetary $\mathrm{PM}_{2.5}$ weighting factor $[€ / \mathrm{kg}]^{* 4}$ & 48 \\
\hline
\end{tabular}

Notes: ${ }^{* 1}$ in accordance to Generalitat de Catalunya (2015); ${ }^{* 2}$ in accordance to EMEP/EEA (2013), assuming EURO V for light commercial vehicles $<3.5 \mathrm{t}$, Tier $3 ;{ }^{* 3}$ average value for year 2015, according to $\operatorname{SENDECO}_{2}(2016) ;{ }^{\star 4}$ in accordance to Holland $e$ al. (2005). 
This fact is due to the discrete nature of the number of tours captured by variable $\left[\frac{N_{i}}{\psi}\right]^{+}$in Equation (2a). The peaks of these boundaries correspond to a variation of the fleet size between both sides of the curve. The night distribution measure, Strategy B, forces that the same area of the city should be visited twice ( $\mu$ fraction at night period and $1-\mu$ fraction at day period). Therefore, the total distance run by the whole fleet is generally higher in Strategy B than in Strategy A. For this reason, Strategy B always presents in this Scenario 1.1 (same fleet of capacity $C=C^{N}=9 \mathrm{~m}^{3}$ ) an increment of the monetary value of emissions ranging from 1.0 to 1.9 . However, the collaborative carrier will experience a reduction of transportation cost (values $0<\eta_{N}<1$ ) when $\mu>0.46$ and the retailer density to be served is $\delta_{i}>10$ receivers $/ \mathrm{km}^{2}$. This fact happens because, in night distribution, the temporal costs incurred by carriers are significantly lower than Strategy A due to the higher cruising speed, and this cost component is generally more important than the distance component. The higher the retailer density $\delta_{i}$ and $\mu$ fraction are; the more efficient Strategy B is. In this Scenario 1.1, Strategy $B$ is able to reduce the carrier cost by more than $30 \%$ with regard to Strategy A $\left(\eta_{N}<0.7\right.$, white area in Figure $\left.3 a\right)$. Figures $4 \mathrm{a}$ and $4 \mathrm{~b}$ represent, respectively, $\eta_{N}$ and $\eta_{E}$ ratio in Scenario 1.2, where a vehicle capacity has set to $C^{N}=25$ $\mathrm{m}^{3}$ in night deliveries. This vehicle technology reduces the total transportation carrier cost with regard to Scenario 1.1 for significant high retailer density and $\mu$ fraction in the domain considered. Interestingly, in this Scenario 1.2, the system can achieve emissions savings as the $\eta_{E}$ ratio ranges between $0.6 \ldots 1.0$ for high retailer density and $\mu$ fraction values. Therefore, night distribution may result in transportation cost savings due to the more productive usage of vehicles in off-peak periods. In order to obtain emission savings, the deployment of a fleet of bigger capacity is recommended. However, this fact is never possible when the density of retailers that will be served at night period is $\delta_{i}<20$ night receivers $/ \mathrm{km}^{2}$, whatever the $\mu$-fraction is. Generally, the variations of $\eta_{N}$ ratio are more sensitive to changes in the fraction of receivers that take part in night distribution $\mu$ when a minimal receiver demand density is ensured. This fact can be noticed in Figures $3 \mathrm{a}$ and $4 \mathrm{a}$ as the $\eta_{N}$ ranges are almost vertical bands when $\delta_{i}>20$ receivers $/ \mathrm{km}^{2}$, despite the discontinuities.

\subsection{Carrier-led Consolidation measure. Strategy C}

The analysis of results in Strategy $C$ are presented in Figures 5-8 with regard to density of receivers and $F\left(u_{\max }\right)$ when the fare $\theta_{C F}$ is set by MinFare criterion defined in Section 2.2. a)

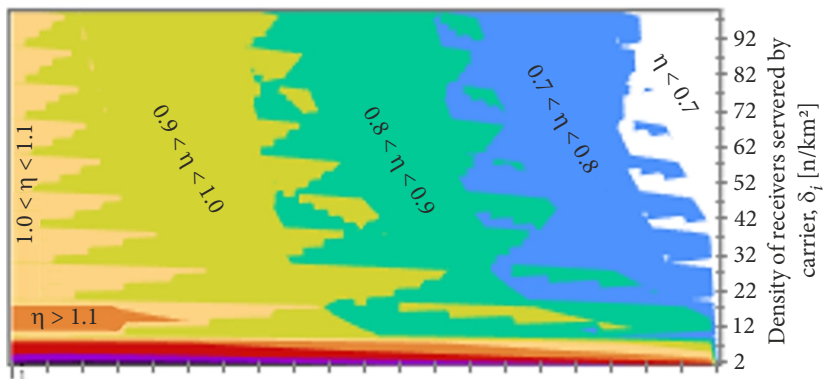

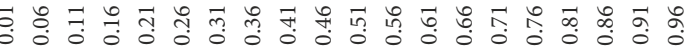

$\mu$

Range of variables $\eta_{N}$ and $\eta_{C}[1 / 100]$

$\square<70 \quad \square$ 70-80 $\square$ 80-90 $\square$ 90-100 $\square$ 100-110 $\square$ 110-120 b)

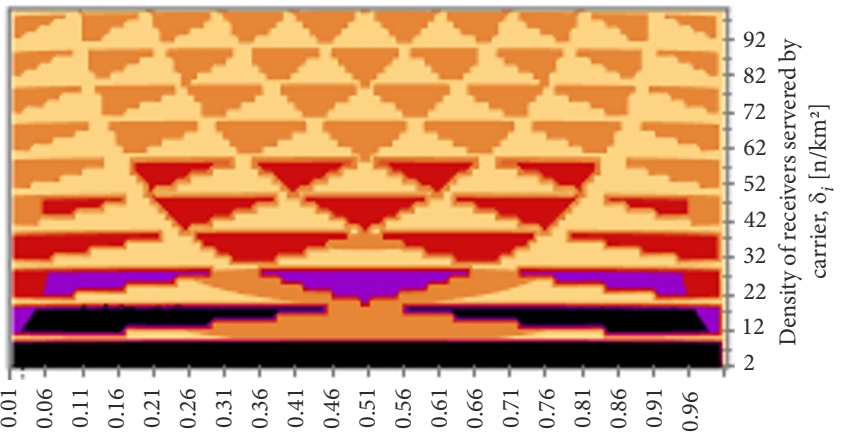

$\mu$

$120-130$

$130-140$

$>140$

Figure 3. Results in Scenario $1.1\left(C^{N}=9 \mathrm{~m}^{3}\right): \mathrm{a}-\eta_{N}$ ratio; $\mathrm{b}-\eta_{E}$ ratio

a)

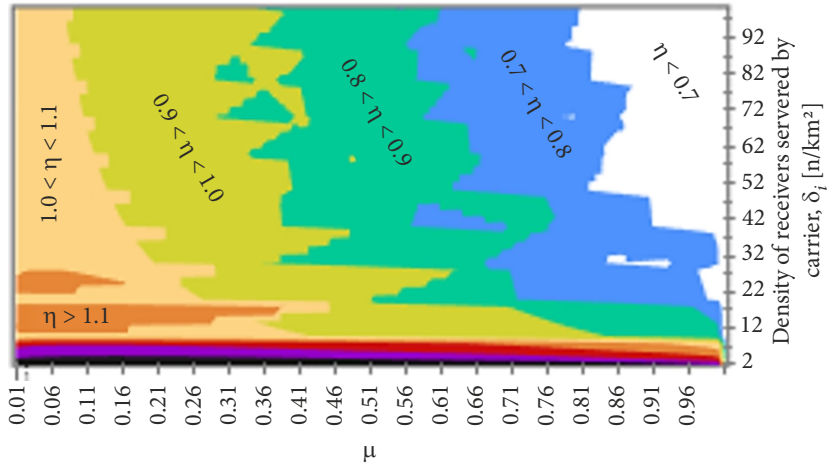

b)

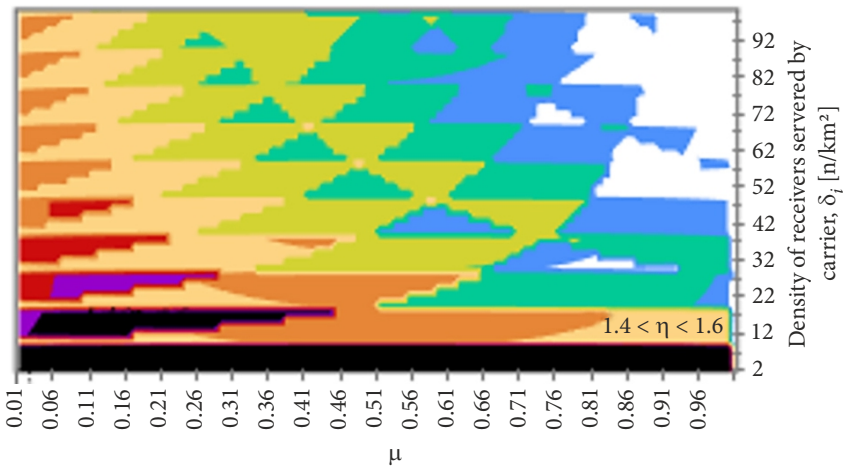

Figure 4. Results in Scenario $1.2\left(C^{N}=25 \mathrm{~m}^{3}\right): \mathrm{a}-\eta_{N}$ ratio; $\mathrm{b}-\eta_{E}$ ratio 
Since the fare $\theta_{C F}$ equals the average unit transportation and facility cost per parcel (routed through $\mathrm{CF}$ ) that CF operator incurs, the variable $\Delta_{C F}$ is always 0 . When CF operator chooses the same fleet used by collaborative carrier (Scenario 2.1, $C^{C F}=9 \mathrm{~m}^{3}$ ), the collaborative carrier will never achieve logistic cost savings $\left(\eta_{C}>1\right.$ in Figure 5a).

a)

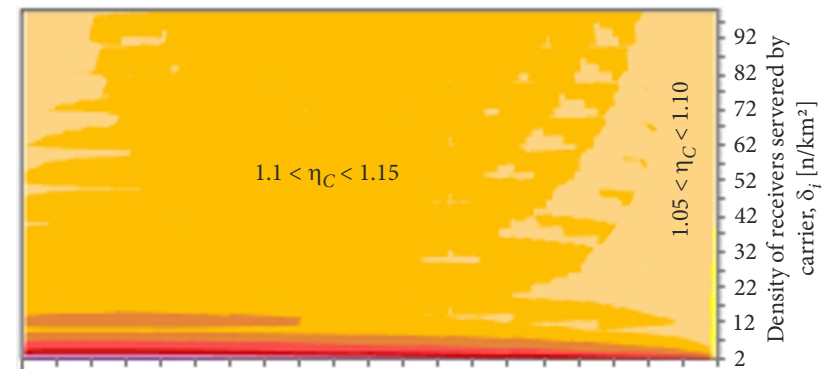

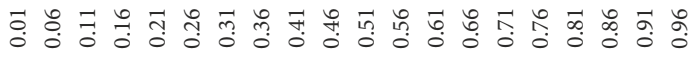

$$
F\left(u_{\max }\right)
$$

The fare to be paid by collaborative carrier $\left(\theta_{C F}>1.20 € /\right.$ parcel in Figure 5b) is always higher than the transportation cost savings that it incurs. In addition to that, there is not generally any benefit in the emissions produced with this strategy. In Figure 8a, we can notice that $\eta_{E, C}>1$ for the general application domain of study $-\delta_{i}, F\left(u_{\max }\right)$.

b)
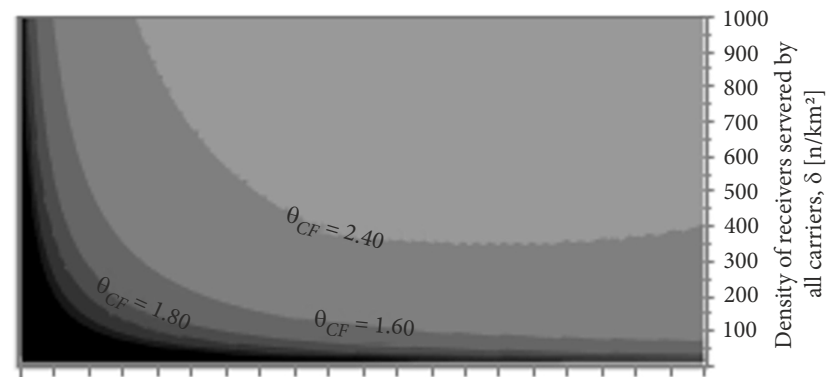

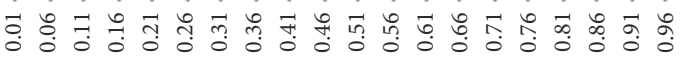

$F\left(u_{\max }\right)$

Range of variables $\eta_{N}$ and $\eta_{C}[1 / 100]$
$\square<70 \quad \square 70-75 \quad \square 75-80$
$\square$ 110-115 $\square$ 115-120
$\square$ 120-125
$\square$ 80-85 $\square$ 85-90
$\square$ 90-95
$\square$ 95-100
$\square 100-105$
$105-110$
125-130 $\square$ 130-135
135-140
$140-145$
$>145$

Range of variables $\theta_{C F}[€ / 100]$

Figure 5. Results in Scenario $2.1\left(C^{C F}=9 \mathrm{~m}^{3}\right)$ with MinFare criterion: $\mathrm{a}-\eta_{C}$ ratio; $\mathrm{b}-$ fare $\theta_{C F}[€]$

a)

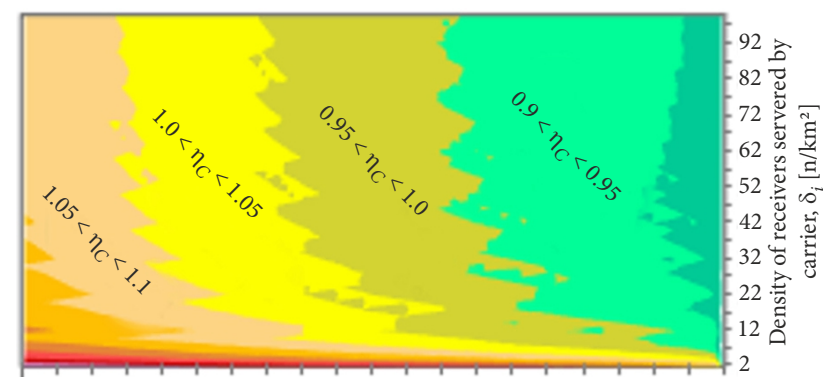

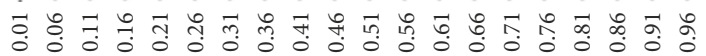

$F\left(u_{\max }\right)$ b)

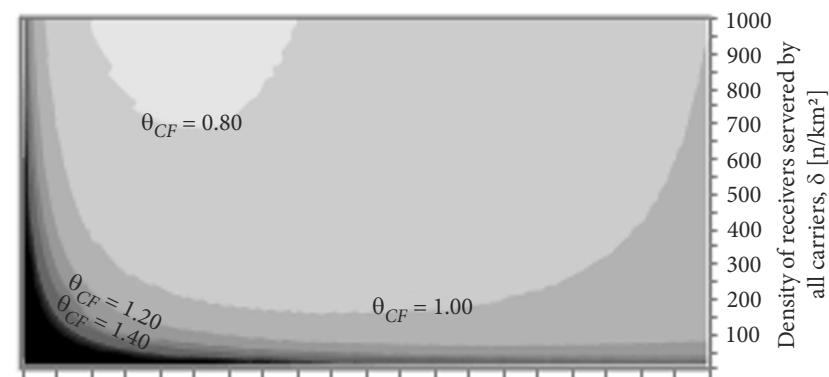

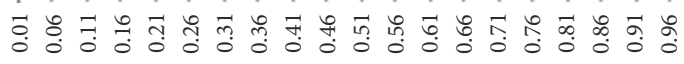

$F\left(u_{\max }\right)$

Figure 6. Results in Scenario $2.2\left(C^{C F}=2.16 \mathrm{~m}^{3}\right)$ with MinFare criterion: $\mathrm{a}-\eta_{C}$ ratio; $\mathrm{b}-$ fare $\theta_{C F}[€]$

a)

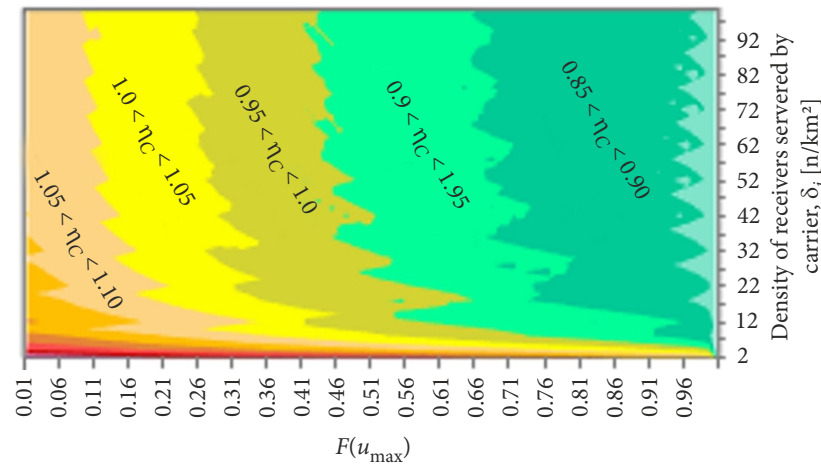

b)

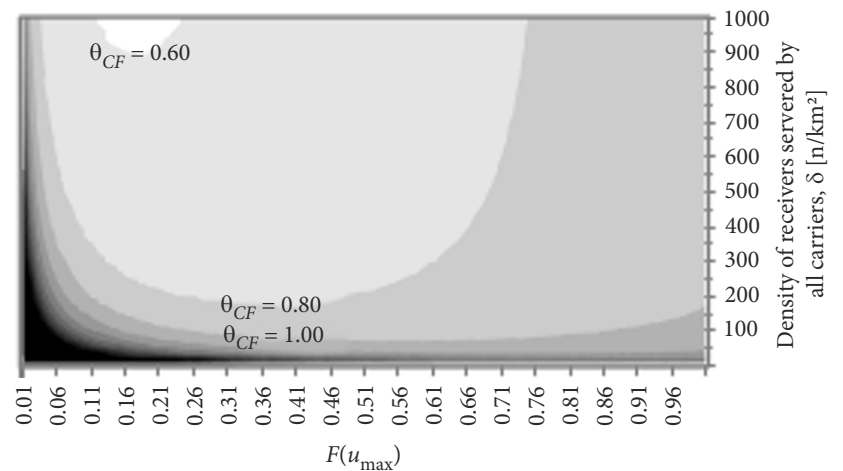

Figure 7. Results in Scenario $2.3\left(C^{C F}=1.2 \mathrm{~m}^{3}\right)$ with MinFare criterion: $\mathrm{a}-\eta_{C}$ ratio; $\mathrm{b}-$ fare $\theta_{C F}[€]$ 
Only when a carrier routes the vast majority of parcels through $\mathrm{CF}$, i.e. $F(u) \rightarrow 1$, we can achieve emissions savings with this strategy (green subdomain in Figure 8a).

In Scenarios 2.2 (electric van) and 2.3 (electric cargobike), the collaborative carrier may experience a positive profitability when moving from Strategy A (regular distribution) to Strategy C. From Figures $6 a$ and $7 a$, the logistic cost reduction of collaborative carrier ranges $0.8<\eta_{C}<1$. We always obtain $\eta_{C} \leq 1$ in Scenario 2.2 when $\delta_{i}>10$ retailers $/ \mathrm{km}^{2}$ and $F\left(u_{\max }\right)>0.65$; and in Scenario 2.3 when $\delta_{i}>9$ retailers $/ \mathrm{km}^{2}$ and $F\left(u_{\max }\right)>0.49$. The profitability of collaborative carrier is the highest in Scenario 2.3. This is due to the input cost parameters associated to the $\mathrm{CF}$ operator fleet. When CF operator runs the local network with a more economically fleet, the necessary fare $\theta_{C F}$ to balance the CF operator profitability does not increase significantly. For instance, the fare in the case of e-cargo bikes (Figure $7 \mathrm{~b}$ ) is lower than $\theta_{C F}<1.00 € /$ parcel in a wide domain of analysis $-\delta_{i}, F\left(u_{\max }\right)$. The fare $\theta_{C F}(P)$ associated to any point $P=\left(d_{i, p}, F(u)_{p}\right)$ in Scenario 2.3

a)

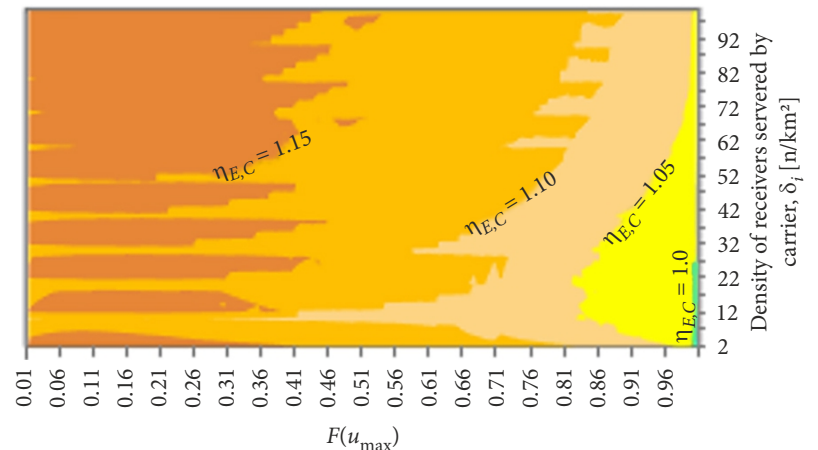

is always lower than corresponding values in Scenario 2.1 (Figure 5b) or Scenario 2.2 (Figure 6b). Therefore, collaborative carrier will pay less for participating in the collaborative consolidation strategy. The results in terms of emission saving are promising when CF operator distributes freight with a fully electric fleet. Both Scenarios 2.2 and 2.3 provide the same values of $\eta_{E, C}$ (Figure $8 \mathrm{~b}$ ) since these scenarios only differ in the capacity of the electric fleet, which does not generate pollutants.

When the fare $\theta_{C F}$ is set by Fare30-70 criterion, the profitability metrics for all stakeholders involved differ from the results obtained by MinFare criterion $\theta_{C F}=$ $z^{C F}$. In Figures $9 \mathrm{a}, 9 \mathrm{~b}$ and $11 \mathrm{a}$ the $\eta_{C}$ ratio, $\Delta_{C F}$ variable (accounting for the CF profitability) and fare $\theta_{C F}$ are respectively plotted for Scenario 2.2 in the same domain of analysis. Figures $10 \mathrm{a}, 10 \mathrm{~b}$ and $11 \mathrm{~b}$ present the corresponding variables for Scenario 2.3. The values of ratios $\eta_{E, C}$ are not presented since they are identical to the ones obtained in Figure $8 \mathrm{~b}$ when MinFare criterion was used. b)

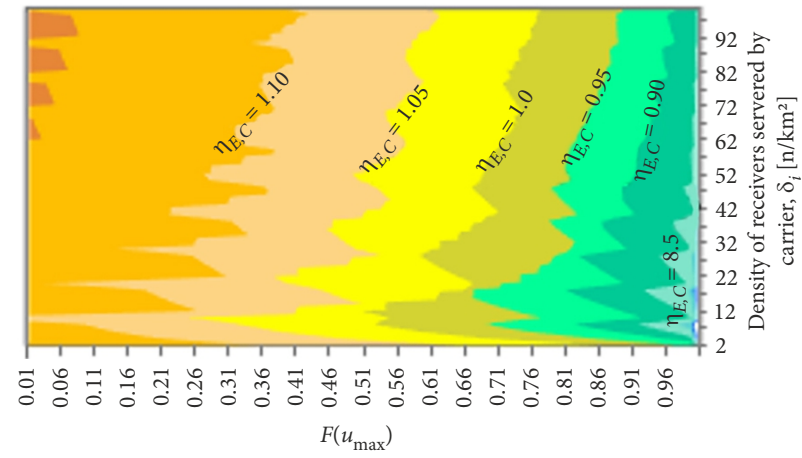

Figure 8. $\eta_{E, C}$ ratio with MinFare criterion: a - results in Scenario $2.1\left(C^{C F}=9 \mathrm{~m}^{3}\right)$; $\mathrm{b}-$ results in Scenarios $2.2\left(C^{C F}=2.16 \mathrm{~m}^{3}\right)$ and $2.3\left(C^{C F}=1.2 \mathrm{~m}^{3}\right)$

a)

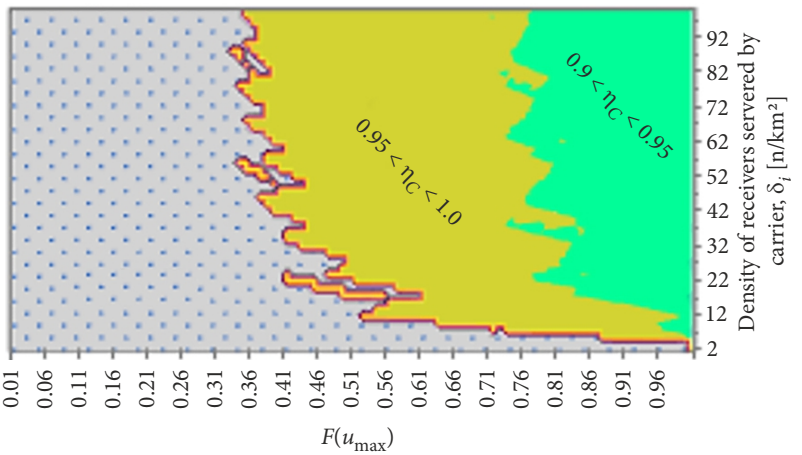

b)

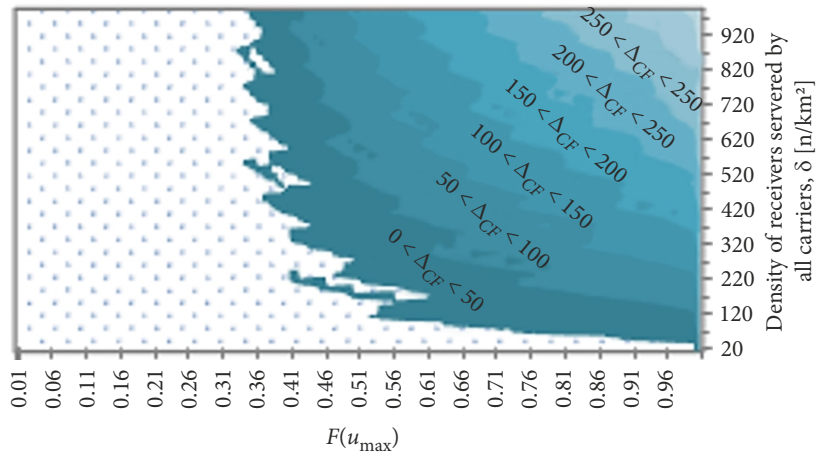

Range of variables $\eta_{N}$ and $\eta_{C}[1 / 100]$

$\square 110-115 \square 115-120 \quad \square 120-125$

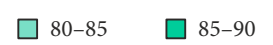

$\square$ 90-95

$\square$ 95-100 $\square$ 100-105

$\square$ 105-110

Range of variables $\theta_{C F}[€ / 100]$

$\square<60 \quad \square$ 60-80 $\square 80-100$
Range of variables $\Delta_{C F}[€ /$ day $]$
$\square$ N.F. $\square 0-50 \quad \square 50-100$

100-120

$120-140$

140-160

$160-180$

180-200

$200-220$

220-240

$>200$

Figure 9. Results in Scenario $2.2\left(C^{C F}=2.4 \mathrm{~m}^{3}\right)$ with Fare $30-70$ criterion: a - $\eta_{C}$ ratio; b - CF operator profitability $\Delta_{C F}[€ /$ day] 
a)

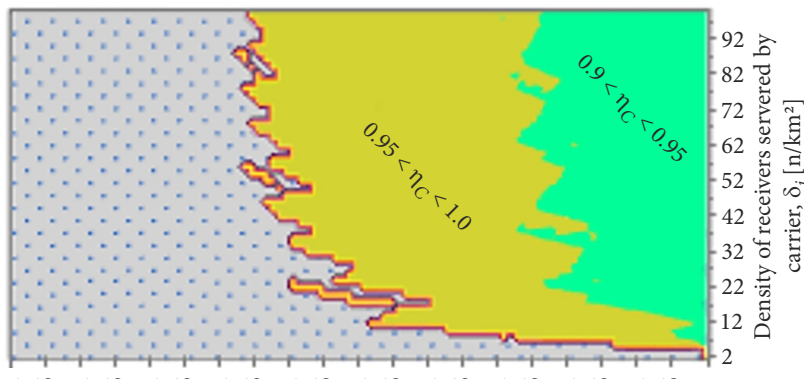

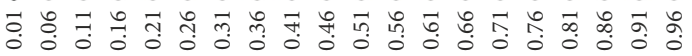

$$
F\left(u_{\max }\right)
$$

Range of variables $\eta_{N}$ and $\eta_{C}[1 / 100]$
$\square<70 \quad \square 70-75 \quad \square 75-80$
$\square$ 110-115 $\square$ 115-120
$120-125$
$\square$ 80-85 $\square 85-90$
$\square$ 125-130 $\square$ 130-135
$\square 90-95$
$\square$ 95-100
$\square$ 100-105
$\square 105-110$

Range of variables $\theta_{C F}[€ / 100]$

$\square<60 \quad \square$ 60-80 $\square$ 80-100 $\square$ 100-120 $\square$ 120-140 $\square$ 140-160

Range of variables $\Delta_{C F}[€ /$ day $]$

Figure 10. Results in Scenario $2.3\left(C^{C F}=1.2 \mathrm{~m}^{3}\right)$ with Fare30-70 criterion: a $-\eta_{C}$ ratio; b - CF operator profitability $\Delta_{C F}[€ /$ day]

a)

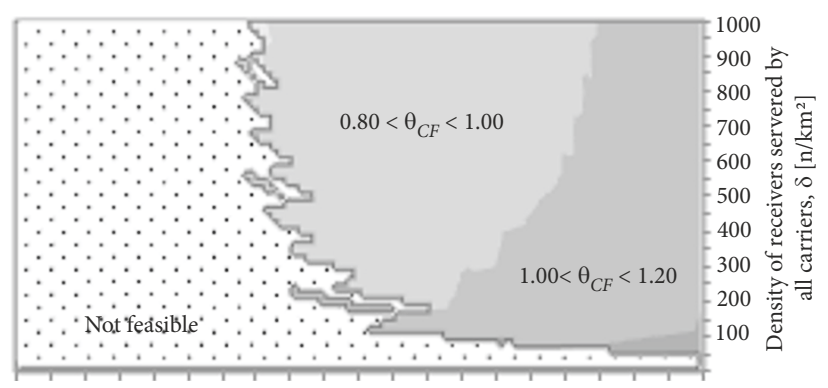

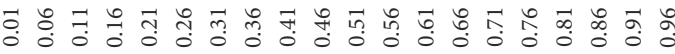
$F\left(u_{\max }\right)$

Range of variables $\theta_{C F}[€ / 100]$ b)

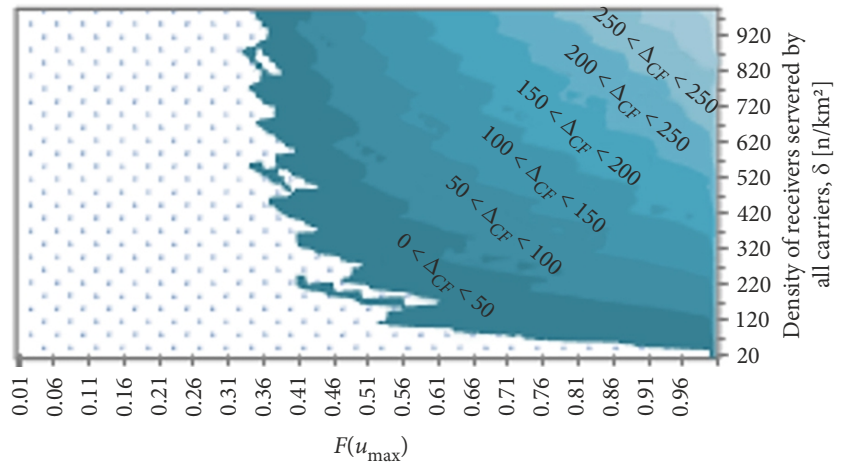

b)

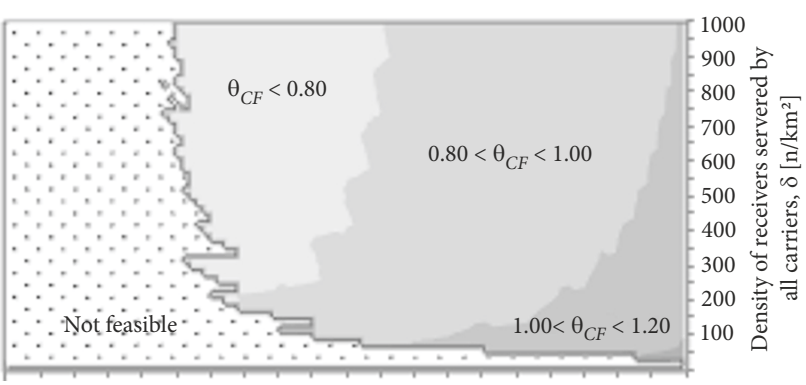

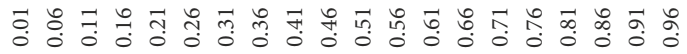

$F\left(u_{\max }\right)$

Figure 11. Fare $\theta_{C F}[€]: \mathrm{a}$ - results in Scenario $2.2\left(C^{C F}=2.4 \mathrm{~m}^{3}\right) ; \mathrm{b}-$ results in Scenario $2.3\left(C^{C F}=1.2 \mathrm{~m}^{3}\right)$

a)

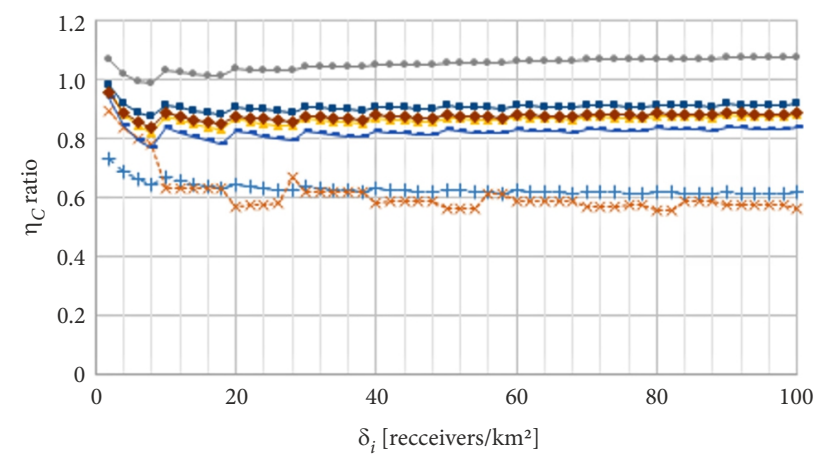

$\begin{array}{ll}--+- & \text { Strategy B. Scenario 1.1 } \\ \longrightarrow- & \text { Strategy C. Scenario 2.1 MinFare } \\ \longrightarrow & \text { Strategy C. Scenario 2.3 MinFare }\end{array}$

$\longrightarrow$ Strategy C. Scenario 2.3 Fare30-70 b)

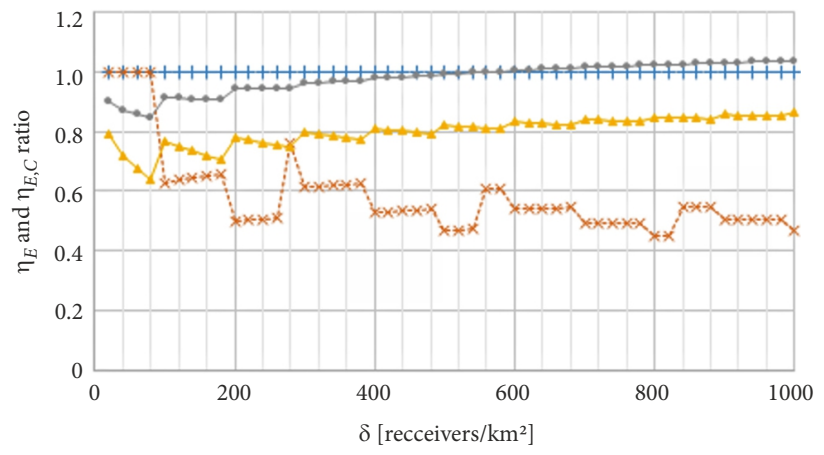

--+- Strategy B. Scenario $1.1 \quad$----x--- Strategy B. Scenario 1.2 $\longrightarrow$ Strategy C. Scenario $2.1 \longrightarrow$ Strategy C. Scenario $2.2 \& 2.3$

Figure 12 . Results when all shipments are made by means of a collaborative strategy: $\mathrm{a}-\eta_{C}$ ratio; $\mathrm{b}-\eta_{E}$ or $\eta_{E, C}$ ratio 
The selection of electric vans $\left(C^{C F}=2.16 \mathrm{~m}^{3}\right)$ used to make deliveries from $\mathrm{CF}$ to final retailers achieve reductions of carrier expenses of $10 \%-\eta_{C}=0.90$, when $F\left(u_{\max }\right) \rightarrow 1$. The transportation cost savings achievements in Scenario 2.3 are slightly higher than Scenario 2.2 , while the region fulfilling $\eta_{C}<0.90$ is wider. In Figures 9-11, there is a wide domain of unfeasible points $\delta_{i}$, $F\left(u_{\max }\right)$ that verify $\Delta z^{C A}<z^{C F}$. It means that the carrier cost saving is lower than the average cost per parcel handled by CF operator at the consolidation strategy. Therefore, this unfeasible domain represents the area in which the proposed business model (Fare30-70 criterion) does not ensure positive profitability for both carrier and CF operator. Out of this domain, the CF operator may experience a positive profitability, with benefits ranging from $0<\Delta_{C F}<405$ (Scenario 2.2) and $0<\Delta_{C F}<550 € /$ day (Scenario 2.3). Reasonably, the fares $\theta_{C F}$ calculated by this criterion are slightly higher than the results provided in Figures $6 \mathrm{~b}$ and $7 \mathrm{~b}$ when MinFare criterion was used.

Scenario 2.1 has neither achieved carrier cost reductions nor emission savings in the general retailer's demand domain of analysis with Fare30-70 criterion. The utilization of the same fleet by carriers and CF operator increases the overall transportation cost incurred by all agents. In addition to that, as a difference from Scenarios 2.2 and 2.3 , the local distribution is made by internal combustion engine powered vehicles that contribute to increase the externalities caused by pollutants. Although new fully electric commercial vehicles will rise in the future years of capacity roughly $C=9 \mathrm{~m}^{3}$, these vehicles will be also used in Strategies A and C. Therefore, the consolidation strategy cannot be justified from this perspective.

\subsection{Comparison of Strategies B and C at full collaboration}

In this section, we analyse the potential achievements when Strategies B or C are implemented considering that all receivers are served by means of a collaborative strategy. It means that when Strategy B or C are considered, there is not any carrier fleet visiting receivers during the day shift (commercial hours). All receivers will be served at night or by means of the CF operator fleet. This situation is considered in the model by $\mu=1$ (Strategy B) or $F\left(u_{\max }\right)=1$ and could not be properly depicted in Figures 3-10 since it represents a severe discontinuity with regard to the rest of the variable domain. In spite of the low probability that this ideal change will happen (some receivers and carriers would be reluctant to move to Strategy B or C as reported in Holguín-Veras et al. 2015), this situation determines the best demand conditions for the application of these strategies. Figures $12 \mathrm{a}$ and $12 \mathrm{~b}$ depict respectively the values of $\eta_{C}$ and $\eta_{E}$ ratios $\left(\eta_{E, C}\right.$ in case of Strategy C) for the range of receiver density considered. The percentage of reduction of carrier cost by means of full collaborative strategies with regard to Strategy $\mathrm{A}$ ( $\eta_{C}$ ratio) is practically constant for all retailer density domain. Indeed, Strategy B is able to reduce the carrier costs by $40 \%$ in both Scenarios 1.1 and 1.2. However, the emission reduc- tion can only be achieved when carriers use a vehicle of a higher capacity (Scenario 1.2). In this Scenario, for high demand density values, the amount of emissions can be reduced by $40 \ldots 50 \%$. A fact that deserves mention is the value $\eta_{E, C}=1$ obtained in the whole domain of analysis in Scenario 1.1. It means that the distribution at night provides the same level of emissions as in the day period when the fleet technology is maintained. This fact happens although cruising speeds are higher at night. The explanation is that the model selected to estimate commercial vehicle emissions (EMEP/EEA 2013) is able to provide different emissions factors for the city access and local phases of the route. However, this model is not sensitive enough to modify emission factors when cruising speeds are increased by $10 \ldots 20 \%$.

The values of $\eta_{C}$ ratio obtained with Strategy $C$ are generally poorer than Strategy B for the same problems and demand assumptions, and they depend on the criterion by which cost savings are divided into carriers and CF operator. The $\eta_{C}$ ratio fluctuates between $(0.78 \ldots 0.96)$. The highest carrier cost reduction is obtained when CF operator manages the local distribution network with electric cargo bikes (Scenario 2.3). Although all carriers would switch to route their shipments through a CF, the utilization of the same fleet in the long-haul and local network (Scenario 2.1) will always increase the carrier cost $\left(\eta_{C}>1\right)$. Nevertheless, a small percentage of emission savings could be obtained for a wide receiver density range.

\section{Conclusions}

In this paper, we analysed the new effects produced by two well-known collaboration measures on the different stakeholders involved in urban distribution: Night distribution and carrier-led consolidation strategies. Both measures are only profitable for all agents when a minimal spatial density of retailers participating in the strategy is achieved. Below this density, some agents incur in higher costs than in regular conditions, that will make them lose competitiveness against similar companies, and therefore, they will no longer take part in this collaborative scheme.

Comparing the results obtained with night distribution (Strategy B) and carrier-led consolidation measure (Strategy C), we may realize that Strategy B generally outperforms Strategy C in terms of transportation cost savings. Night distribution does neither include a new facility cost nor time penalties in the system and allows a better productivity of resources. However, it is mandatory to foster incentive programs promoting unattended deliveries in order to gain the acceptance of retailers to receive products at night periods. In the case of the night-time distribution of goods, collaborative carriers that move from day to night distribution may reduce the transportation costs due to the higher cruising speed of vehicles in the night period. The highest carrier transportation cost reduction with regard to Strategy A is roughly $30 \%$, when a collaborative carrier also distributes some shipments during the day period $\mu<1$. This achievement is highly similar to the practical results achieved in pilot 
test conducted in New York, Bogotá and Sao Pablo. However, results show that this percentage of transportation cost reduction can achieve the $40 \%-\eta_{N}=0.60$, when all shipments are switched to night deliveries $\mu=1$. It has been demonstrated that the reduction of carrier cost is more sensitive to the variations of the fraction of receivers switched to night distribution rather than variations in receiver density. This is only true when a minimal density of receivers is ensured $-\delta_{i}>20$ receivers $/ \mathrm{km}^{2}$. Nevertheless, from the emission perspective, night distribution needs to consolidate more shipments in vehicles and, therefore, the usage of bigger trucks in night period to achieve emission savings is required. Carriers do not want to operate with vehicles of greater capacity because, by using smaller vehicles, they assure the reduction of costs (Holguín-Veras 2002). Moreover, larger vehicles have usually restrictions in some parts of the cities (especially old city centres with narrow streets). In this regard, public administrations could play an important role providing incentives to purchase these larger (and silent) vehicles to be used during the night. The main challenge for the development of night-time distribution is to encourage retailers to support this new paradigm. In this paper we have demonstrated that its implementation has positive economic effects on carriers and environment, but the effect on receivers has not been addressed by developed models. Therefore, the latter needs external economic mechanisms (incentives) to justify its involvement. In the long run, once the initial incentives have been provided, night distribution can reconcile the goals of carriers, receivers, shippers and the city without any type of incentive, overcharge or temporary penalty.

Regarding consolidation strategies, results show that these are only valid when carriers transfer a large fraction of goods through the consolidation centre $F\left(u_{\max }\right)$. Consequently, it is not a universal measure for any city, since it needs a strong involvement of carriers and receivers in the short term to present positive results. For each implementation, it is necessary to verify that a minimum return is achieved for a carrier, CF operator and emissions savings for the city. From the sensitivity analysis, the maximal expenses reduction for carriers is roughly $15 . . .20 \%$ in the domain of analysis when the vast majority of goods are routed through the CF and the fare is set to only compensate $\mathrm{CF}$ operator costs. However, if we oblige that CF operator will receive a minimal profit (the $30 \%$ of the total transport cost savings experienced by the carrier, including the fare $\theta_{C F}$ payment), the collaborative carrier expense is only reduced by $10 \ldots 15 \%$ at the most. In this strategy, the capacity of the fleet used for distributing parcels from the CF to the final retailers should be lower than the corresponding to the carrier in the access phase. However, the CF fleet must present lower unit transportation costs and emissions factors than carrier fleet. In fact, the usage of electric cargo bikes or small electric vans is recommended. The development of this measure requires private contracts between the carriers and the CF operator to agree the fare to pay for a package sent through the $\mathrm{CF}$, variable that plays a very important role in the profitability of both agents. However, the development of this strategy can be carried out without the direct participation of those agents that control the economic decisions of goods consumption: receivers and suppliers.

\section{References}

Allen, J.; Browne, M.; Woodburn, A.; Leonardi, J. 2014. A review of urban consolidation centres in the supply chain based on a case study approach, Supply Chain Forum: An International Journal 15(4): 100-112.

https://doi.org/10.1080/16258312.2014.11517361

Allen, J.; Browne, M.; Woodburn, A.; Leonardi, J. 2012. The role of urban consolidation centres in sustainable freight transport, Transport Reviews 32(4): 473-490.

https://doi.org/10.1080/01441647.2012.688074

Allen, J.; Piecyk, M.; Piotrowska, M.; McLeod, F.; Cherrett, T.; Ghali, K.; Nguyen, T.; Bektas, T.; Bates, O.; Friday, A.; Wise, S.; Austwick, M. 2018. Understanding the impact of e-commerce on last-mile light goods vehicle activity in urban areas: the case of London, Transportation Research Part D: Transport and Environment 61: 325-338.

https://doi.org/10.1016/j.trd.2017.07.020

Allen, J.; Thorne, G.; Browne, M. 2007. BESTUFS: Good Practice Guide on Urban Freight Transport. European Commission under the 6 th Framework Programme for Research and Technological Demonstration. BESTUFS Consortium. 84 p. Available from Internet: http://www.bestufs.net

Barone, R.; Roach, E. 2016. Why Goods Movement Matters: Strategies for Moving Goods in Metropolitan Areas. Regional Plan Association (RPA) and Volvo Research and Educational Foundations (VREF). 28 p. Available from Internet: http:// goodsmovementmatters.org

Brom, M. A.; Holguín-Veras, J.; Hodge, S. D. 2011. Off-hour deliveries in Manhattan, New York City: experiences of pilot test participants, Transportation Research Record: Journal of the Transportation Research Board 2238: 77-85.

https://doi.org/10.3141/2238-10

Browne, M.; Sweet, M.; Woodburn, A.; Allen, J. 2005. Urban Freight Consolidation Centres: Final Report. Transport Studies Group, University of Westminster, UK. $191 \mathrm{p}$.

Chen, Q.; Lin, J.; Kawamura, K. 2012. Comparison of urban cooperative delivery and direct delivery strategies, Transportation Research Record: Journal of the Transportation Research Board 2288: 28-39. https://doi.org/10.3141/2288-04

CISLOG. 2015. Avaliação do Projeto-Piloto de Entregas Noturnas no Município de São Paulo. Série Cadernos Técnicos 18. Centro de Inovação em Sistemas Logísticos (CISLOG), São Paulo, Brasil. 76 p. (in Portuguese).

CITYLOG. 2013. Sustainability and Efficiency of City Logistics. Project ID: 233756, Funded under: FP7-TRANSPORT. Available from Internet: https://cordis.europa.eu/project/ rcn/93637_en.html

DHL. 2013. DHL Express Packing Guide: Protect your Shipment with Good and Quality Packaging. Deutsche Post AG / DHL Operations B.V. / DHL International GmbH. 24 p.

EMEP/EEA. 2013. EMEP/EEA Air Pollutant Emission Inventory Guidebook 2013: Technical Guidance to Prepare National Emission Inventories. EEA Technical report No 12/2013. European Monitoring and Evaluation Programme (EMEP), European Environment Agency (EEA) 26 p.

https://doi.org/10.2800/92722 
Estrada, M.; Roca-Riu, M. 2017. Stakeholder's profitability of carrier-led consolidation strategies in urban goods distribution, Transportation Research Part E: Logistics and Transportation Review 104: 165-188.

https://doi.org/10.1016/j.tre.2017.06.009

Foltyński, M. 2016. Management tool for streamlining city logistics, Transportation Research Procedia 16: 89-103.

https://doi.org/10.1016/j.trpro.2016.11.010

Holland, M.; Pye, S.; Watkiss, P.; Droste-Franke, B.; Bickel, P. 2005. Damages per Tonne Emission of $\mathrm{PM}_{2.5}, \mathrm{NH}_{3}, \mathrm{SO}_{2}, \mathrm{NO}_{x}$ and VOCs from each EU25 Member State (excluding Cyprus) and Surrounding Seas. Service Contract for Carrying out Cost-Benefit Analysis of Air Quality Related Issues, in Particular in the Clean Air for Europe (CAFE) Programme. European Commission DG Environment. 31 p. Available from Internet: http://ec.europa.eu/environment/archives/cafe/activities/pdf/cafe_cba_externalities.pdf

Generalitat de Catalunya. 2015. Observatori de costos del transport de mercaderies per carretera a Catalunya, Butlletí de transports 72. Setembre 2015. Barcelona, Catalunya, Espanya. Available from Internet: http://territori.gencat.cat/web/.content/home/01_departament/estadistica/publicacions_estadistiques/territori_i_mobilitat/observatori_del_costos_del_ transport_de_mercaderies_per_carretera/butlleti_72_setembre_2015.pdf (in Catalan).

Gonzalez-Feliu, J.; Morana, J. 2011. Collaborative transportation sharing: from theory to practice via a case study from France, in J. Yearwood, A. Stranieri (Eds.). Technologies for Supporting Reasoning Communities and Collaborative Decision Making: Cooperative Approaches, 252-271.

https://doi.org/10.4018/978-1-60960-091-4.ch014

Gonzalez-Feliu, J.; Morana, J.; Salanova Grau, J.-M.; Ma, T.-Y. 2013a. Design and scenario assessment for collaborative logistics and freight transport Systems, Rivista Internazionale Di Economia dei Trasporti / International Journal of Transport Economics 40(2): 207-240.

Gonzalez-Feliu, J.; Salanova Grau, J.-M.; Morana J.; Mitsakis, E. 2013b. Urban logistics pooling viability analysis via a multicriteria multiactor method, in M. V. Petit Lavall, F. Martínez Sanz, A. Recalde Castells (Eds.). La Nueva Ordenación del Mercado de Transporte, 871-886.

Gonzalez-Feliu, J.; Salanova, J.-M. 2012. Defining and evaluating collaborative urban freight transportation systems, ProcediaSocial and Behavioral Sciences 39: 172-183.

https://doi.org/10.1016/j.sbspro.2012.03.099

Gonzalez-Feliu, J.; Salanova Grau, J.-M.; Beziat, A. 2014. A location-based accessibility analysis to estimate the suitability of urban consolidation facilities, International Journal of Urban Sciences 18(2): 166-185.

https://doi.org/10.1080/12265934.2014.930673

Holguín-Veras, J. 2011. Urban delivery industry response to cordon pricing, time-distance pricing, and carrier-receiver policies in competitive markets, Transportation Research Part A: Policy and Practice 45(8): 802-824.

https://doi.org/10.1016/j.tra.2011.06.008

Holguín-Veras, J. 2008. Necessary conditions for off-hour deliveries and the effectiveness of urban freight road pricing and alternative financial policies in competitive markets, Transportation Research Part A: Policy and Practice 42(2): 392-413. https://doi.org/10.1016/j.tra.2007.10.008

Holguín-Veras, J. 2002. Revealed preference analysis of commercial vehicle choice process, Journal of Transportation Engineering 128(4): 336-346.

https://doi.org/10.1061/(ASCE)0733-947X(2002)128:4(336)
Holguín-Veras, J.; Amaya-Leal, J.; Wojtowicz, J.; Jaller, M; González-Calderón, C.; Sánchez-Díaz, I; Wang, X.; Haake, D. G.; Rhodes, S. S.; Frazier, R. J.; Nick, M. K.; Dack, J.; Casinelli, L.; Browne, M. 2015. Improving Freight System Performance in Metropolitan Areas: A Planning Guide. National Cooperative Freight Research Program (NCFRP) Report 33. Transportation Research Board, Washington, DC, US. 200 p. https://doi.org/10.17226/22159

Holguín-Veras, J.; Aros-Vera, F. 2015. Self-supported freight demand management: pricing and incentives, EURO Journal on Transportation and Logistics 4(2): 237-260.

https://doi.org/10.1007/s13676-013-0041-1

Holguín-Veras, J.; Wang, X. (C.).; Sánchez-Díaz, I.; Campbell, S.; Hodge, S. D.; Jaller, M.; Wojtowicz, J. 2017a. Fostering unassisted off-hour deliveries: the role of incentives, Transportation Research Part A: Policy and Practice 102: 172-187. https://doi.org/10.1016/j.tra.2017.04.005

Holguín-Veras, J.; Campbell, S.; Kalahasthi, L.; Wang, C. 2017b. Role and potential of a trusted vendor certification program to foster adoption of unassisted off-hour deliveries, Transportation Research Part A: Policy and Practice 102: 157-171. https://doi.org/10.1016/j.tra.2016.09.011

Holguín-Veras, J.; Encarnación, T.; González-Calderón, C. A.; Winebrake, J.; Wang, C.; Kyle, S.; Herazo-Padilla, N.; Kalahasthi, L.; Adarme, W.; Cantillo,V.; Yoshizaki, H.; Garrido, R. 2016. Direct impacts of off-hour deliveries on urban freight emissions, Transportation Research Part D: Transport and Environment 61: 84-103. https://doi.org/10.1016/j.trd.2016.10.013

Holguín-Veras, J.; Ozbay, K.; Kornhauser, A.; Brom, M. A.; Iyer, S.; Yushimito, W. F.; Ukkusuri, S.; Allen, B.; Silas, M. A. 2011. Overall impacts of off-hour delivery programs in new york city metropolitan area, Transportation Research Record: Journal of the Transportation Research Board 2238: 68-76. https://doi.org/10.3141/2238-09

Holguín-Veras, J.; Sánchez-Díaz, I. 2016. Freight demand management and the potential of receiver-led consolidation programs, Transportation Research Part A: Policy and Practice 84: 109-130. https://doi.org/10.1016/j.tra.2015.06.013

Holguín-Veras, J.; Silas, M.; Polimeni, J. 2008a. An investigation into the attitudinal factors determining participation in cooperative multi-carrier delivery initiatives, in E. Taniguchi, R. G. Thomson (Eds.). Innovations in City Logistics, 55-68.

Holguín-Veras, J.; Silas, M.; Polimeni, J.; Cruz, B. 2008b. An investigation on the effectiveness of joint receiver-carrier policies to increase truck traffic in the off-peak hours. Part II: the behavior of carriers, Networks and Spatial Economics 8(4): 327-354. https://doi.org/10.1007/s11067-006-9011-6

Holguín-Veras, J.; Silas, M.; Polimeni, J.; Cruz, B. 2007. An investigation on the effectiveness of joint receiver-carrier policies to increase truck traffic in the off-peak hours. Part I: the behavior of receivers, Networks and Spatial Economics 7(3): 277-295. https://doi.org/10.1007/s11067-006-9002-7

Holguín-Veras, J.; Wojtowicz, J.; Wang, X. (C.).; Jaller, M.; Ban, X. (J.).; Aros, F.; Campbell, S.; Yang, X.; Sanchez, I.; Amaya, J.; González-Calderón, C.; Marquis, R.; Hodge, S.; Maguire, T.; Marsico, M.; Zhang, S.; Rothbard, S.; Ozbay, K.; Morgul, E. F.; Iyer, S.; Xie, K.; Ozguven, E. E. 2013. Integrative Freight Demand Management in the New York City Metropolitan Area: Implementation Phase. Final Report. US Department of Transportation. 459 p. Available from Internet: http:// cite.rpi.edu/en/news/16-off-hour-delivery

Janjevic, M.; Ndiaye, A. 2017. Investigating the theoretical costrelationships of urban consolidation centres for their users, 
Transportation Research Part A: Policy and Practice 102: 98118. https://doi.org/10.1016/j.tra.2016.10.027

Johansen, B. G.; Andersen, J.; Eidhammer, O.; Verlinde, S.; Filipe, L. N.; Da Rocha, J.; Sardinha, N.; Rodrigues, Ó.; Gogas, M.; Papoutsis, K.; Nathanail, E.; McLeod, F.; RocaRiu, M.; Estrada, M.; Eris, B.; Balm, S.; Moolenburgh, E. 2014. STRAIGHTSOL Deliverable: D5.1 Demonstration Assessments. EU-Funded Project from the Seventh Programme for Research, Technological Development and Demonstration under Grant Agreement No. 285295. 245 p. Available from Internet: http://www.straightsol.eu/deliverables.htm

Kawamura, K. 2014. Urban planning with city logistics, in E. Taniguchi, R. G. Thompson (Eds.). City Logistics: Mapping the Future, 41-54.

Kawamura, K.; Lu, Y. 2007. Evaluation of delivery consolidation in U.S. urban areas with logistics cost analysis, Transportation Research Record: Journal of the Transportation Research Board 2008: 34-42. https://doi.org/10.3141/2008-05

Kin, B.; Verlinde, S.; Van Lier, T.; Macharis, C. 2016. Is there life after subsidy for an urban consolidation centre? An investigation of the total costs and benefits of a privately-initiated concept, Transportation Research Procedia 12: 357-369. https://doi.org/10.1016/j.trpro.2016.02.072

Köhler, U. 2001. City logistics in Germany, in E. Taniguchi, R. G. Thompson (Eds.). City Logistics, 203-214.

Lebeau, P.; Verlinde, S.; Macharis, C.; Van Mierlo, J. 2017. How can authorities support urban consolidation centres? A review of the accompanying measures, Journal of Urbanism: International Research on Placemaking and Urban Sustainability 10(14): 468-486.

https://doi.org/10.1080/17549175.2017.1310747

Navarro, C.; Roca-Riu, M.; Furió, S.; Estrada, M. 2016. Designing new models for energy efficiency in urban freight transport for smart cities and its application to the Spanish case, Transportation Research Procedia 12: 314-324. https://doi.org/10.1016/j.trpro.2016.02.068

NCFRP. 2012. Guidebook for Understanding Urban Goods Movement. National Cooperative Freight Research Program (NCFRP) Report 14. Transportation Research Board, Washington, DC, US. 107 p. https://dx.doi.org/10.17226/14648

Paddeu, D.; Fadda, P.; Fancello, G.; Parkhurst, G.; Ricci, M. 2014. Reduced urban traffic and emissions within urban consolidation centre schemes: the case of Bristol, Transportation Research Procedia 3: 508-517.

https://doi.org/10.1016/j.trpro.2014.10.032

Quak, H.; Tavasszy, L. 2011. Customized solutions for sustainable city logistics: the viability of urban freight consolidation centres, in J. Van Nunen, P. Huijbregts, P. Rietveld (Eds.). Transitions Towards Sustainable Mobility, 213-233. https://doi.org/10.1007/978-3-642-21192-8_12

Robusté, F.; Daganzo, C. F.; Souleyrette, R. R. 1990. Implementing vehicle routing models, Transportation Research Part B: Methodological 24(4): 263-286.

https://doi.org/10.1016/0191-2615(90)90002-G

Roca-Riu, M.; Estrada, M. 2012. An evaluation of urban consolidation centers through logistics systems analysis in circumstances where companies have equal market shares, Procedia - Social and Behavioral Sciences 39: 796-806. https://doi.org/10.1016/j.sbspro.2012.03.148

Roca-Riu, M.; Estrada, M.; Fernández, E. 2016. An evaluation of urban consolidation centers through continuous analysis with non-equal market share companies, Transportation Research Procedia 12: 370-382.

https://doi.org/10.1016/j.trpro.2016.02.073
Saberi, M.; Verbas, İ. Ö. 2012. Continuous approximation model for the vehicle routing problem for emissions minimization at the strategic level, Journal of Transportation Engineering 138(11): 1368-1376.

https://doi.org/10.1061/(ASCE)TE.1943-5436.0000442

Schoemaker, J.; Allen, J.; Huschebeck, M.; Monigl, J. 2006. Quantification of Urban Freight Transport Effects I. European Commission under the 6th Framework Programme for Research and Technological Demonstration. BESTUFS Consortium. 76 p. Available from Internet: http://www.bestufs.net/download/ BESTUFS_II/key_issuesII/BESTUF_Quantification_of_effects.pdf

$\mathrm{SENDECO}_{2}$. 2016. Sistema Europeo de Negociación de $\mathrm{CO}_{2}$. Available from Internet: https://www.sendeco2.com (in Spanish).

Silas, M. A.; Holguín-Veras, J. 2009. Behavioral microsimulation formulation for analysis and design of off-hour delivery policies in urban areas, Transportation Research Record: Journal of the Transportation Research Board 2097: 43-50. https://doi.org/10.3141/2097-06

SMARTFREIGHT. 2016. Smart Freight Transport in Urban Areas. Project ID: 216353. Funded under FP7-ICT. Available from Internet: https://cordis.europa.eu/project/rcn/85574_en.html

STRAIGHTSOL. 2014. Strategies and Measures for Smarter Urban Freight Solutions: STRAIGHTSOL. EU-Funded Project from the Seventh Programme for Research, Technological Development and Demonstration under Grant Agreement No. 285295. Available from Internet: http://www.straightsol.eu

SUGAR. 2011. City Logistics Best Practices: a Handbook for Authorities. Sustainable Urban Goods Logistics Achieved by Regional and Local Policies (SUGAR). 276 p. Available from Internet: http://www.sugarlogistics.eu/pliki/handbook.pdf

Taniguchi, E. 2014. Concepts of city logistics for sustainable and liveable cities, Procedia - Social and Behavioral Sciences 151: 310-317. https://doi.org/10.1016/j.sbspro.2014.10.029

Universidad Nacional de Colombia. 2015. Desarrollo de una consultoría para diseñar e implementar un piloto de cargue $y$ descargue nocturno en empresas de dos unidades de planeamiento zonal (UPZ) de Bogotá. Resumen Ejecutivo. Bogotá, Colombia. (in Spanish).

Van Audenhove, F.-J.; De Jongh, S.; Durance, M. 2015. Urban Logistics: How to Unlock Value from Last Mile Delivery for Cities, Transporters and Retailers. 12 p. Available from Internet: http://www.adlittle.com/sites/default/files/viewpoints/ ADL_Urban_Logistics.pdf

Van Rooijen, T.; Quak, H. 2010. Local impacts of a new urban consolidation centre - the case of Binnenstadservice.nl, Procedia - Social and Behavioral Sciences 2(3): 5967-5979. https://doi.org/10.1016/j.sbspro.2010.04.011

Yannis, G.; Golias, J.; Antoniou, C. 2006. Effects of urban delivery restrictions on traffic movements, Transportation Planning and Technology 29(4): 295-311. https://doi.org/10.1080/03081060600905566 